\title{
Effect of Dopants on Zirconia Stabilization-An X-ray Absorption Study: I, Trivalent Dopants
}

\author{
Ping $\mathrm{Li}^{\star}$ and I-Wei Chen* \\ Department of Materials Science and Engineering, University of Michigan, \\ Ann Arbor, Michigan $48109-2136$
}

James E. Penner-Hahn

Department of Chemistry, University of Michigan, Ann Arbor, Michigan 48109-1055

Local atomic structures of $\mathrm{Zr}$ and dopant cations in zirconia solid solutions with $\mathrm{Fe}_{2} \mathrm{O}_{3}, \mathrm{Ga}_{2} \mathrm{O}_{3}, \mathrm{Y}_{2} \mathrm{O}_{3}$, and $\mathrm{Gd}_{2} \mathrm{O}_{3}$ have been determined. The $\mathrm{Zr}$ ions in both partially stabilized tetragonal and fully stabilized cubic zirconia have their own characteristic structures which are dopant-independent. The dopant cations substitute for $\mathrm{Zr}$ ions despite severe local distortions necessitated by the large difference in dopant-O distance and $\mathrm{Zr}-\mathrm{O}$ distance. Dopant ionic size determines the preferred locations of oxygen vacancies. Vacancies introduced by oversized dopants ( $Y$ and $G d$ ) are located as nearest neighbors to $\mathrm{Zr}$ atoms, leaving 8-fold oxygen coordination to dopant cations. Undersized dopants (Fe and $\mathrm{Ga}$ ) compete with $\mathrm{Zr}$ ions for the oxygen vacancies in zirconia, resulting in 6-fold oxygen coordination and a large disturbance to the surrounding next nearest neighbors. Since oxygen vacancies associated with $\mathrm{Zr}$ can provide stability for tetragonal and cubic zirconia, these results suggest an explanation for the observation that oversized trivalent dopants are more effective than undersized trivalent dopants in stabilizing cubic and tetragonal phases.

\section{Introduction}

$\mathbf{P}$ ARTIALLY stabilized tetragonal and fully stabilized cubic zirconia are important engineering ceramics with numerous applications. A variety of cation dopants are known to serve as stabilizers, which prevent the undesirable transformation of these materials during cooling to low temperatures. ${ }^{1-5}$ Although there has been considerable research on alloy development and the mechanical and electrical characteristics of zirconia, the atomistic origins of phase stabilization remain unclear. Using $\mathrm{X}$-ray absorption spectroscopy (XAS) techniques, we have obtained local structures around $\mathrm{Zr}$ ions in four zirconia polymorphs. ${ }^{6}$ The configuration of oxygen vacancies and the static and thermal distortion of bonding in these polymorphs have also been elucidated. ${ }^{7,8}$ The present paper and the following two corroborate the previous studies and further describe the local structures of the dopant cations. Our intent is to derive from these structural studies a better understanding of the stabilization process of zirconia.

Aliovalent cation dopants are generally believed to substitute for $\mathrm{Zr}$ ion in the cation network, creating oxygen vacancies for

W. White-contributing editor

\footnotetext{
Manuscript No. 194671. Received April 16, 1993; approved August 23, 1993.

Supported by the National Science Foundation under Grant No. DMR-9119598. NSLS is operated by the Department of Energy, Office of Basic Energy Science, Division of Chemical Sciences. Beamline X9-A is supported by the NIH, Biomedical Resource Technology Program.

"Member, American Ceramic Society.
}

charge compensation. It has been suggested that this process is directly responsible for the stability of doped $\mathrm{ZrO}_{2}$. The stabilization process in this case is rationalized by a crystal chemistry model, ${ }^{9}$ which postulates that the dopant cations tend to form 8 -fold coordination with oxygen, leaving oxygen vacancies to the $\mathrm{Zr}$ ions. Since the strongly covalent nature of the $\mathrm{Zr}-\mathrm{O}$ bond favors 7 -fold $\mathrm{Zr}$ coordination, the high-temperature polymorphs are stabilized when the average $\mathrm{Zr}$ coordination number is reduced, by doping, to a sufficiently low value, typically around 7.5, at the tetragonal/cubic phase boundary. In this model, stabilization rests on the availability of oxygen vacancies and the size misfit associated with doping. Cations which stabilize the high-temperature polymorphs typically have a larger ionic size, a lower charge state, and a higher ionicity, than $\mathrm{Zr}$.

Although there is some experimental support for the above model, ${ }^{4,10.11}$ several aspects remain unexplained. First, the stabilization effect of undersized dopants (such as $\mathrm{Fe}^{3+}, \mathrm{Ga}^{3+}$, and $\mathrm{Al}^{3+}$ ), which are not likely to be 8 -fold coordinated, cannot be understood using this model. Second, the stabilization effect of tetravalent cations, both oversized ones (such as $\mathrm{Ce}^{4+}$ and $\mathrm{Th}^{4+}$ ) and undersized ones (such as $\mathrm{Ge}^{4+}$ and $\mathrm{Ti}^{4+}$ ), which do not introduce oxygen vacancies, cannot be understood either. Third, the model does not address the issue of stabilization of the tetragonal phase, which typically has a very low dopant concentration, and thus very few oxygen vacancies.

In principle, some of the above issues can be resolved if the local structures around $\mathrm{Zr}$ and dopant cations are known for all of the polymorphs. Most structural investigations of zirconia, however, have utilized diffraction techniques which often cannot distinguish between dopant and host cations, especially when the dopant concentration is low or when its atomic number is close to that of $\mathrm{Zr}$ (e.g., Y). In such cases, these studies have employed models which treat host and dopant cations as randomly distributed, with identical distortions from their reference lattice sites. ${ }^{11-15}$ Not surprisingly, such studies have not been able to provide much insight into the problems of interest here. X-ray absorption spectroscopy, including extended X-ray absorption fine structure (EXAFS) spectroscopy and X-ray near edge structure (XANES) spectroscopy, on the other hand, is a local probe that is element specific and sensitive to dopants of rather low concentrations. Previous XAS studies on zirconia systems have shown, for example, that the $\mathrm{Zr}-\mathrm{O}$ bond lengths are significantly different from the dopant $-\mathrm{O}$ bond lengths. ${ }^{16-25}$ These studies, however, were mostly focused on fully stabilized cubic zirconia, with oversized dopant cations (Y, Gd, and other rare-earth elements). In the present work, a systematic XAS study has been undertaken for both fully stabilized cubic and partially stabilized tetragonal zirconia. Undersized and oversized dopants, of a valence state from $3+$ to $5+$, have been investigated. The results using trivalent dopants $\left(\mathrm{Gd}^{3+}, \mathrm{Y}^{3+}\right.$, $\mathrm{Fe}^{3+}$, and $\mathrm{Ga}^{3+}$, ranked in the order of decreasing ionic size) are reported in this paper. 


\section{Experimental Procedure}

\section{(1) Materials}

Ultrafine powders are required for successful X-ray absorption studies. In this study, single-phase (tetragonal and cubic) powders with compositions of 3 and $10 \mathrm{~mol} \% \mathrm{M}_{2} \mathrm{O}_{3}(\mathrm{M}=\mathrm{Gd}$, $\mathrm{Y}, \mathrm{Fe}$, and $\mathrm{Ga}$ ) dopants were synthesized by the following method. The metal oxide was used as a dopant source for Y(III) and $\mathrm{Gd}(\mathrm{III})$; the nitrates were used for $\mathrm{Fe}(\mathrm{III})$ and $\mathrm{Ga}(\mathrm{III}) . \mathrm{A}$ solution was first prepared by dissolving dopant oxides in hot dilute $\mathrm{HNO}_{3}$ (or using a dopant nitrate solution) and mixing this solution with an appropriate volume of $\mathrm{ZrOCl}_{2}$ solution. Dilute $\mathrm{NH}_{4} \mathrm{OH}$ was then added slowly, with $\mathrm{H}_{2} \mathrm{O}_{2}$ and sugar as dispersing agents, to effect coprecipitation without agglomeration. The mixtures were slowly dried at $200^{\circ} \mathrm{C}$ and calcined at $650^{\circ} \mathrm{C}$ for $4 \mathrm{~h}$, which was usually sufficient to fully form zirconia solid solutions. Higher calcination temperatures were sometimes attempted after it was first verified that phase-pure powders could still be obtained after such heat treatment. The samples are designated as $3 \mathrm{Fe} 06$ or $3 \mathrm{Y} 13$, and so on, with the first set of numbers indicating the dopant concentration (in mol\%) and the second set of numbers indicating the calcination temperature (in $100^{\circ} \mathrm{C}$ ). A summary of the composition, calcination temperature, and phase identification for the samples used in this study is given in Table $I$.

Attempts for phase identification were first made by X-ray diffraction (XRD). Only samples which appeared to contain a single monoclinic, tetragonal or cubic phase according to XRD were used in the subsequent XAS studies. However, when the particle size is too small, as in the case after low-temperature calcination at $650^{\circ}$ to $850^{\circ} \mathrm{C}$, it is difficult to distinguish the tetragonal form from the cubic one, or to measure lattice constants because of severe peak broadening. The existence of the cubic phase was ruled out in some cases when the powder, after high-temperature calcination $\left(1300^{\circ} \mathrm{C}\right)$, transformed to the monoclinic phase. (The cubic phase is not expected to transform after high-temperature calcination.) Pure $\mathrm{ZrO}_{2}, \mathrm{Gd}_{2} \mathrm{O}_{3}$, $\mathrm{Y}_{2} \mathrm{O}_{3}, \mathrm{Fe}_{2} \mathrm{O}_{3}$, and $\mathrm{Ga}_{2} \mathrm{O}_{3}$ were used directly as model compounds in the XAS studies. For later reference, the crystallographic data of these model compounds are listed in Table II.

\section{(2) X-ray Absorption Measurements}

$\mathrm{X}$-ray absorption measurements at the $\mathrm{Zr}$-, Y-, Fe- and Ga- $K$ edges were made on a Beamline X10-C, and at the Gd- $L_{\mathrm{III}}$ edge on an X9-A, at the National Synchrotron Light Source (NSLS) at Brookhaven National Laboratory under normal operating conditions (2.5 GeV, 100-200 mA). Energy selection was accomplished by using a double-crystal monochromator with $\mathrm{Si}(333$ ) crystals (for $\mathrm{Zr}$ and $\mathrm{Y}$ ) or Si(111) crystals (for $\mathrm{Gd}, \mathrm{Ga}$, and $\mathrm{Fe}$ ). A Ti filter was used as a high pass filter for the $\mathrm{Zr}$ - and $Y-K$ edge measurements to remove the fundamental (ca. $6 \mathrm{keV}$ ) and pass the first harmonic (ca. $18 \mathrm{keV}$ ) of the beam. In the measurements of $\mathrm{Gd}, \mathrm{Ga}$, and $\mathrm{Fe}$ edges, detuning of $50 \%$ inci- dent beam above the absorption edges was used to reduce the harmonic content of the beam. At X9-A, there was a harmonic rejection mirror and the monochromator was run fully tuned.

Spectra for $\mathrm{Fe}$ in 3-mol\%- $\mathrm{Fe}_{2} \mathrm{O}_{3}$-doped zirconia were measured in the fluorescence mode using a large solid-angle ion chamber as a fluorescence detector. All other measurements were made in the transmission mode, using an ion chamber filled with $\mathrm{Ar}$ for the $\mathrm{Zr}$ and $\mathrm{Y}$ edges, and $\mathrm{N}_{2}$ for the other edges. Energy calibration was accomplished by placing two ion chambers behind the sample. A calibration standard (the oxide of the appropriate cation) was placed between them, thus allowing the absorption spectrum of the standard to be recorded at the same time as the sample spectrum. The calibration was defined by assigning the maximum inflection point of absorption edges of the standards as follows: $\mathrm{ZrO}_{2}(17998 \mathrm{eV}), \mathrm{Fe}_{2} \mathrm{O}_{3}(7112 \mathrm{eV})$, $\mathrm{Ga}_{2} \mathrm{O}_{3}(10367 \mathrm{eV}), \mathrm{Y}_{2} \mathrm{O}_{3}(17038 \mathrm{eV})$, and $\mathrm{Gd}_{2} \mathrm{O}_{3}(7243 \mathrm{eV}){ }^{26}$ All spectra were measured at room temperature.

Powder samples of doped $\mathrm{ZrO}_{2}$ were diluted with boron nitride powder so that the total X-ray absorbance was $63 \%$ above each absorption edge. They were then pressed into an aluminum sample cell $(2 \mathrm{~mm}$ thick $\times 3 \mathrm{~mm}$ high $\times 25 \mathrm{~mm}$ wide) with $X$-ray transparent windows. About $12 \mathrm{mg}$ of powder was used for $\mathrm{Zr}-K$ edge, $5 \mathrm{mg}$ for $\mathrm{Gd}-L_{\mathrm{III}}$ edge, $40 \mathrm{mg}$ for $\mathrm{Y}-K$ edge, and $12 \mathrm{mg}$ for $\mathrm{Ga}-K$ edge transmission measurements. About $200 \mathrm{mg}$ of powder was used for $\mathrm{Fe}-K$ edge fluorescence samples.

\section{(3) Data Analysis}

The EXAFS spectra were analyzed using the standard EXAFS equation:27,28

$\chi(k)=\sum_{j} \frac{N_{\mathrm{j}}}{k R_{j}^{2}} F_{j}(k) e^{-2 \sigma_{j}^{2} k^{2}} e^{-2 R_{j} / \lambda} \sin \left[2 k R_{j}+\phi_{j}(k)\right]$

where $F_{j}(k)$ is the backscattering amplitude from each of the $N_{j}$ neighboring atoms of the $j$ th type at distance $R_{j}$ with a meansquare relative displacement $\sigma_{j}^{2}$, and $\phi_{j}(k)$ is the total phase shift experienced by the photoelectron which includes contributions from both the scatterer and absorber. The factor $\exp \left(-2 R_{j} / \lambda\right)$, where $\lambda$ is the photoelectron mean free path, is used here to account for inelastic scattering. The photoelectron wave vector is related to the photon energy, $E$, by

$$
k=\sqrt{8 \pi^{2} m\left(E-E_{0}\right) / h^{2}}
$$

where $m$ is electron mass and $h$ is Planck's constant. Threshold energy values (at $k=0$ ), $E_{0}$, were assigned as $18015 \mathrm{eV}$ for the $\mathrm{Zr}-K$ edge, $7130 \mathrm{eV}$ for the $\mathrm{Fe}-K$ edge, $10385 \mathrm{eV}$ for the $\mathrm{Ga}-K$ edge, $17055 \mathrm{eV}$ for the Y- $K$ edge, and $7260 \mathrm{eV}$ for the Gd- $L_{\text {III }}$ edge. Qualitative comparisons of data can also be made by referring to the Fourier transform (FT) of the EXAFS data into the real space, giving a pseudoradial distribution function around the absorbing atom. However, since the EXAFS phase shift function is carried over by the Fourier transformation, the

Table I. Phase Identification of the Zirconia Samples with Trivalent Dopants

\begin{tabular}{|c|c|c|c|c|}
\hline Sample & $\begin{array}{c}\text { Powder } \\
\text { composition }\end{array}$ & $\begin{array}{l}\text { Calcination } \\
\text { temp }\left({ }^{\circ} \mathrm{C}\right)\end{array}$ & $\begin{array}{c}\text { Phase } \\
\text { identification }\end{array}$ & $\begin{array}{c}\text { Lattice } \\
\text { constants }(\AA)\end{array}$ \\
\hline $\mathrm{ZrO}_{2}$ & $100 \% \mathrm{ZrO}_{2}$ & 1300 & $m$ & $a=5.148, b=5.200, c=5.322, \beta=99.2^{\circ}$ \\
\hline $\begin{array}{l}3 \mathrm{Ga} 08 \\
3 \mathrm{Gal3} \\
10 \mathrm{Ga} 07\end{array}$ & $\begin{array}{l}3 \mathrm{~mol} \% \mathrm{Ga}_{2} \mathrm{O}_{3} \\
3 \mathrm{~mol} \% \mathrm{Ga}_{2} \mathrm{O}_{3} \\
10 \mathrm{~mol} \% \mathrm{Ga}_{2} \mathrm{O}_{3}\end{array}$ & $\begin{array}{r}850 \\
1300 \\
700\end{array}$ & $\begin{array}{l}t \\
m+\beta-\mathrm{Ga}_{2} \mathrm{O}_{3} \\
t+c(?)+\beta-\mathrm{Ga}_{2} \mathrm{O}_{3}\end{array}$ & $a=5.150, b=5.198, c=5.325, \beta=99.2^{\circ}$ \\
\hline $\begin{array}{l}3 \mathrm{Fe} 06 \\
3 \mathrm{Fe} 13 \\
10 \mathrm{Fe} 06\end{array}$ & $\begin{array}{l}3 \mathrm{~mol} \% \mathrm{Fe}_{2} \mathrm{O}_{3} \\
3 \mathrm{~mol} \% \mathrm{Fe}_{2} \mathrm{O}_{3} \\
10 \mathrm{~mol} \% \mathrm{Fe}_{2} \mathrm{O}_{3}\end{array}$ & $\begin{array}{r}650 \\
1300 \\
650\end{array}$ & $\begin{array}{l}t \\
m+\alpha-\mathrm{Fe}_{2} \mathrm{O}_{3} \\
t+c(?)+\alpha-\mathrm{Fe}_{2} \mathrm{O}_{3}\end{array}$ & $a=5.149, b=5.196, c=5.323, \beta=99.2^{\circ}$ \\
\hline $\begin{array}{l}3 \mathrm{Y} 13 \\
10 \mathrm{Y} 13\end{array}$ & $\begin{array}{l}3 \mathrm{~mol} \% \mathrm{Y}_{2} \mathrm{O}_{3} \\
10 \mathrm{~mol}_{2} \mathrm{Y}_{2} \mathrm{O}_{3}\end{array}$ & $\begin{array}{l}1300 \\
1300\end{array}$ & $\begin{array}{l}t \\
c\end{array}$ & $\begin{array}{l}a=5.1060, c=5.1808 \\
a=5.1486\end{array}$ \\
\hline $\begin{array}{l}3 \mathrm{Gd} 13 \\
10 \mathrm{Gd} 13\end{array}$ & $\begin{array}{l}3 \mathrm{~mol} \% \mathrm{Gd}_{2} \mathrm{O}_{3} \\
10 \mathrm{~mol} \% \mathrm{Gd}_{2} \mathrm{O}_{3}\end{array}$ & $\begin{array}{l}1300 \\
1300\end{array}$ & $\begin{array}{l}t \\
c\end{array}$ & $\begin{array}{l}a=5.1079, c=5.1903 \\
a=5.1603\end{array}$ \\
\hline
\end{tabular}


Table II. Crystallographic Data of Model Compounds

\begin{tabular}{llll}
\hline Compound & \multicolumn{1}{c}{ Structure } & Cation-oxygen bond lengths $(\AA)$ & Ref. \\
\hline $\mathrm{Ga}_{2} \mathrm{O}_{3}$ & Monoclinic $(\beta)$ & $1.80 \times 1,1.83 \times 2,1.85 \times 1,1.95 \times 3,2.02 \times 1$, & 36 \\
& & $2.08 \times 2$, average $=1.93 \times 5$ & 35 \\
$\mathrm{Fe}_{2} \mathrm{O}_{3}$ & Rhombohedral $(\alpha)$ & $1.945 \times 3,2.116 \times 3$, average $=2.03 \times 6$ & 32 \\
$\mathrm{Y}_{2} \mathrm{O}_{3}$ & C-type & $2.243 \times 6,2.268 \times 2,2.288 \times 2,2.337 \times 2$, & Present study* \\
& & average $=2.28 \times 6$ & 31 \\
$\mathrm{Gd}_{2} \mathrm{O}_{3}$ & C-type & Average $=2.34 \times 6$ & $2.051 \times 1,2.057 \times 1,2.151 \times 1,2.163 \times 1,2.189 \times 1$, \\
$\mathrm{ZrO}_{2}$ & Monoclinic $(\beta)$ & $2.222 \times 1,2.285 \times 1$, average $=2.16 \times 7$ & \\
\end{tabular}

$*^{*} a=10.826 \AA$

Fourier transform peaks are shifted by ca. $0.5 \AA$ to lower distance.

When the scattering environment in the unknown is similar to that in a model compound, the amplitude and phase functions $(F(k) \exp (-2 R / \lambda)$ and $\phi(k))$ can be determined empirically. The unknown is then fitted using a nonlinear least-squares algorithm to determine the bond distance $(R)$, coordination number (CN, or $N$ in Eq. (1)), and the relative bond length dispersion or Debye-Waller factor $\left(\Delta \sigma^{2}\right)$ with reference to the model compound. (All fits utilized $k^{3}$ weighted data over the $k$ range from $\sim 3$ to $\sim 13 \AA^{-1}$.) This approach was used for all of the cationoxygen shells, with the parent cation oxide as the model compound. For the dopant-cation shell, however, the environment is dominated by dopant- $\mathrm{Zr}$ scattering, which cannot be simulated by any reference model compound. Hence, data from the dopant-cation shells were analyzed by using a theoretical model, in which amplitude and phase shift functions of dopant--Zr scattering were calculated using the FEFF program (version 3.0$)^{29}$ with a distance of $3.620 \AA$ (the $\mathrm{Zr}-\mathrm{Zr}$ distance in $t-\mathrm{ZrO}_{2}$ ). Quantitative information on $R, \mathrm{CN}$, and the absolute bond dispersion $\sigma^{2}$ can then be obtained. (Fourier filtered window values for each shell of interest are shown in Tables III-V.)

It should be noted that since $\mathrm{CN}$ and $\sigma^{2}$ are highly correlated, the absolute $\mathrm{CN}$ value obtained from fitting is not particularly reliable, having an accuracy of about $20 \% .{ }^{27}$ In our data-fitting process, $\mathrm{CN}$ and bond dispersion were allowed to float first to obtain rough values; then the $\mathrm{CN}$ was fixed at a reasonable value to obtain the comparable $\sigma^{2}$ or $\Delta \sigma^{2}$ values. A large Debye-Waller factor may arise either because of structural distortion upon the introduction of a dopant or because of chemical disorder due to the different scattering factors of the host and dopant. These effects are difficult to differentiate in the analysis except in some special cases noted later. On the other hand, the bond distance is highly accurate and can always be used for quantitative comparison.

For analysis of the XANES region, the spectra were normalized as follows. ${ }^{30}$ First, a single three-order polynomial was subtracted from the data and the result was then multiplied by a scale factor. The polynomial coefficients and the scale factor were chosen so as to minimize, in a least-squares sense, the deviations between the data and tabulated X-ray absorption coefficients both below and well above the edge.

Since XANES probes more directly the density of unoccupied electronic states, it can be exploited, as a complementary technique to EXAFS, to throw light on many stereochemical features of the coordination polyhedron around the probe atom. These include in the best case bonding configuration, ligandfield symmetry and valency state. XANES theory, however, is more demanding than EXAFS because the potential must be treated to all orders, and it is not yet sufficiently well-developed to allow routine fitting of the experimental data to quantify structural or electronic information on the compounds. Thus, only qualitative interpretation based on some currently accepted empirical notions is attempted for the XANES data.

Table III. Fitting Results of Zr EXAFS for Zirconia with Trivalent Dopants

\begin{tabular}{|c|c|c|c|c|c|c|}
\hline Sample & Phase & Bonding & $\Delta R_{\text {thl }}(\dot{\AA})$ & $R(\AA)$ & $\mathrm{CN}^{*}$ & $\Delta \sigma^{2}$ or $\sigma^{2}\left(\AA^{2}\right)^{\dagger}$ \\
\hline $3 \mathrm{Fe} 13$ & $m+\alpha^{\ddagger}$ & $\begin{array}{l}\mathrm{Zr}-\mathrm{O} \\
\mathrm{Zr}-\mathrm{Zr}\end{array}$ & $\begin{array}{l}1.0-2.2 \\
2.5-4.0\end{array}$ & $\begin{array}{l}2.15 \\
3.46 \\
3.99 \\
4.50\end{array}$ & $\begin{array}{l}7.0 \\
7.0 \\
4.0 \\
1.0\end{array}$ & $\begin{array}{l}0.0021 \\
0.0055 \\
0.0135\end{array}$ \\
\hline $3 \mathrm{Fe} 06$ & $t$ & $\begin{array}{l}\mathrm{Zr}-\mathrm{O}_{\mathrm{I}} \\
\mathrm{Zr} \text {-cation }\end{array}$ & $\begin{array}{l}1.0-1.9 \\
2.7-3.8\end{array}$ & $\begin{array}{l}2.10 \\
3.62\end{array}$ & $\begin{array}{r}4.0 \\
12.0\end{array}$ & $\begin{array}{r}-0.0048 \\
0.0102\end{array}$ \\
\hline 3 Gal3 & $m+\beta^{s}$ & $\begin{array}{l}\mathrm{Zr}-\mathrm{O} \\
\mathrm{Zr}-\mathrm{Zr}\end{array}$ & $\begin{array}{l}1.0-2.2 \\
2.5-4.0\end{array}$ & $\begin{array}{l}2.15 \\
3.46 \\
4.00 \\
4.54\end{array}$ & $\begin{array}{l}7.0 \\
7.0 \\
4.0 \\
1.0\end{array}$ & $\begin{array}{l}0.0048 \\
0.0055 \\
0.0128\end{array}$ \\
\hline $3 \mathrm{Ga} 08$ & $t$ & $\begin{array}{l}\mathrm{Zr}-\mathrm{O}_{\mathrm{I}} \\
\mathrm{Zr} \text {-cation }\end{array}$ & $\begin{array}{l}1.0-1.9 \\
2.6-3.8\end{array}$ & $\begin{array}{l}2.10 \\
3.62\end{array}$ & $\begin{array}{r}4.0 \\
12.0\end{array}$ & $\begin{array}{r}-0.0035 \\
0.0086\end{array}$ \\
\hline $3 Y 13$ & $t$ & $\begin{array}{l}\mathrm{Zr}-\mathrm{O}_{\mathrm{I}} \\
\mathrm{Zr} \text {-cation }\end{array}$ & $\begin{array}{l}1.0-2.0 \\
2.6-3.8\end{array}$ & $\begin{array}{l}2.11 \\
3.62\end{array}$ & $\begin{array}{r}4.0 \\
12.0\end{array}$ & $\begin{array}{r}-0.0031 \\
0.0076\end{array}$ \\
\hline $10 Y 13$ & $c$ & $\begin{array}{l}\mathrm{Zr}-\mathrm{O} \\
\mathrm{Zr}-\text { cation }\end{array}$ & $\begin{array}{l}1.0-2.0 \\
2.5-3.6\end{array}$ & $\begin{array}{l}2.15 \\
3.58\end{array}$ & $\begin{array}{r}7.0 \\
12.0\end{array}$ & $\begin{array}{r}-0.0018 \\
0.0108\end{array}$ \\
\hline $3 G d 13$ & $t$ & $\begin{array}{l}\mathrm{Zr}-\mathrm{O}_{\mathrm{I}} \\
\mathrm{Zr}-\text { cation }\end{array}$ & $\begin{array}{l}1.0-1.9 \\
2.6-3.8\end{array}$ & $\begin{array}{l}2.11 \\
3.63\end{array}$ & $\begin{array}{r}4.0 \\
12.0\end{array}$ & $\begin{array}{r}-0.0043 \\
0.0086\end{array}$ \\
\hline $10 \mathrm{Gd} 13$ & $c$ & $\begin{array}{l}\mathrm{Zr}-\mathrm{O} \\
\mathrm{Zr}-\text { cation }\end{array}$ & $\begin{array}{l}1.0-1.9 \\
2.5-3.6\end{array}$ & $\begin{array}{l}2.15 \\
3.60\end{array}$ & $\begin{array}{r}7.0 \\
12.0\end{array}$ & $\begin{array}{r}-0.0013 \\
0.0149\end{array}$ \\
\hline
\end{tabular}

*Fixed at shown values during fitting. ${ }^{+} \Delta \sigma^{2}$ : relative $\mathrm{Zr}-\mathrm{O}$ length dispersion with reference to $0.01 \AA^{2}$ for $m-\mathrm{ZrO}_{2}$. $\sigma^{2}$ : absolute $\mathrm{Zr}-\mathrm{cation}$ distance dispersion. ${ }^{\ddagger} \alpha-\mathrm{Fe}_{2} \mathrm{O}_{3},{ }^{*} \beta-\mathrm{Ga}_{2} \mathrm{O}_{3}$. 
Table IV. Dopant-O Bonding in Zirconia with Trivalent Dopants and in Parent Oxides

\begin{tabular}{|c|c|c|c|c|c|c|}
\hline Sample* & Phase & M-O & $\Delta R_{\text {fik }}(\AA)$ & (A) & $\mathrm{CN}^{\dagger}$ & \\
\hline $\begin{array}{l}\text { Pure C } \\
3 \mathrm{Gd} 13 \\
\text { 10Gd1 }\end{array}$ & $t$ & & & & & \\
\hline $\mathrm{Y}_{2} \mathrm{O}_{3}$ & $\begin{array}{l}\text { C-type } \\
t \\
c\end{array}$ & & & & $\begin{array}{l}8.0 \\
8.0\end{array}$ & $\begin{array}{l}0.00 \\
0.0023 \\
0.0032\end{array}$ \\
\hline $\begin{array}{l}\text { Pure } \mathrm{Fe}_{2} \mathrm{O}_{3} \\
3 \mathrm{Fe} 06 \\
3 \mathrm{Fe} 13\end{array}$ & $\begin{array}{l}\alpha-\mathrm{Fe}_{2} \mathrm{O}_{3} \\
t \\
m+\alpha\end{array}$ & $\begin{array}{l}\mathrm{Fe}-\mathrm{O} \\
\mathrm{Fe}-\mathrm{O} \\
\mathrm{Fe}-\mathrm{O}\end{array}$ & & $\begin{array}{l}2.03 \\
2.01 \\
2.03\end{array}$ & $\begin{array}{l}6.0 \\
6.0 \\
6.0\end{array}$ & $\begin{array}{c}0.00 \\
-0.0022 \\
-0.0012\end{array}$ \\
\hline $\begin{array}{l}\text { Pure } \mathrm{Ga}_{2} \mathrm{O}_{3} \\
3 \mathrm{Ga08} \\
3 \mathrm{Ga} 13\end{array}$ & $\begin{array}{l}\beta-\mathrm{Ga}_{2} \mathrm{O}_{3} \\
t \\
m+\beta\end{array}$ & $\begin{array}{l}\mathrm{Ga}-\mathrm{O} \\
\mathrm{Ga}-\mathrm{O} \\
\mathrm{Ga}-\mathrm{O}\end{array}$ & & $\begin{array}{l}1.93 \\
1.95 \\
1.94\end{array}$ & $\begin{array}{l}5.0 \\
6.0 \\
5.0\end{array}$ & $\begin{array}{l}0.00 \\
-0.0010 \\
-0.0021\end{array}$ \\
\hline
\end{tabular}

*Crystallographic data of pure oxides (see Table II) used as models. 'Fixed at shown values during fitting. 'Relative cation- $O$ length dispersion with reference to the parent oxide.

Table V. EXAFS Results of Dopant-Cation Shell in Gd-/Y-Doped Zirconia

\begin{tabular}{lllllll}
\hline \multicolumn{1}{c}{ Sample } & Phase & Cation-cation & $\Delta R_{\text {flu }}(\AA)$ & $R(\AA)$ & $\mathrm{CN}^{*}$ & $\sigma^{2}\left(\AA^{2}\right)$ \\
\hline 3Gd13 & $t$ & Gd-cation & $2.7-3.7$ & 3.62 & 12.0 & 0.0081 \\
10Gd13 & $c$ & Gd-cation & $2.7-3.7$ & 3.62 & 12.0 & 0.0086 \\
3Y13 & $t$ & Y-cation & $2.7-3.8$ & 3.62 & 12.0 & 0.0069 \\
10Y13 & $c$ & Y-cation & $2.7-3.7$ & 3.62 & 12.0 & 0.0074 \\
\hline
\end{tabular}

*Fixed during fitting.

\section{Results}

\section{(1) X-ray Diffraction}

The results of phase identification and lattice parameters are given in Table I. All of the XRD patterns of the low-temperature $\left(650^{\circ}\right.$ to $\left.850^{\circ} \mathrm{C}\right)$ calcined powders show a similar set of broadened peaks but no evidence for the monoclinic phase. Three representative patterns are shown in Fig. 1. Although their lattice parameters were not determined, these powders were calcined again at higher temperatures in order to sharpen the peaks by crystallite coarsening, which facilitated their phase identification and lattice constant determination.

The lattice parameters of stabilized cubic zirconia are larger for $\mathrm{Gd}^{3+}$ than for $\mathrm{Y}^{3+}$ as expected based on the size of these oversized dopant cations. For a given concentration of Gd and $\mathrm{Y}$, the $c / a$ ratio of the tetragonal unit cell is independent of the dopant type. These results are consistent with previous studies. ${ }^{4,5}$ Powders of $3-\mathrm{mol} \%-\mathrm{Fe}_{2} \mathrm{O}_{3}$ - and $-\mathrm{Ga}_{2} \mathrm{O}_{3}$-stabilized tetragonal zirconia calcined at $1300^{\circ} \mathrm{C}$ showed sharp peaks of monoclinic reflections with lattice parameters $(a, b, c$, and $\beta)$ which are almost dopant-independent and similar to those of pure monoclinic zirconia (Table I). Later, by XAS, we also identified the presence of the dopant oxides, $\mathrm{Fe}_{2} \mathrm{O}_{3}$ and $\mathrm{Ga}_{2} \mathrm{O}_{3}$, respectively, in these powders. Thus, although $\mathrm{Fe}$ and $\mathrm{Ga}$ solutes can be retained in the tetragonal zirconia at lower calcination temperatures, the solubility of these undersized dopants must have been exceeded during high-temperature calcination, causing $\mathrm{Fe}_{2} \mathrm{O}_{3}$ and $\mathrm{Ga}_{2} \mathrm{O}_{3}$ to separate from the tetragonal phase, even though there was no evidence for $\mathrm{Fe}_{2} \mathrm{O}_{3}$ and $\mathrm{Ga}_{2} \mathrm{O}_{3}$ in the XRD. Lastly, we found the $10-\mathrm{mol} \%-\mathrm{Fe}_{2} \mathrm{O}_{3}-$ and $-\mathrm{Ga}_{2} \mathrm{O}_{3}$-stabilized zirconia powders, calcined at $650^{\circ}$ and $700^{\circ} \mathrm{C}$, respectively, already showed a trace of $\mathrm{Fe}_{2} \mathrm{O}_{3}$ and $\mathrm{Ga}_{2} \mathrm{O}_{3}$ by XRD.

Inspection of these results reveals the following trend regarding the dependence of zirconia stability on dopant size. Undersized dopants have lower solubility $(<3 \mathrm{~mol} \%)$ in zirconia and their supersaturated tetragonal solid solutions can be maintained only at relatively low calcination temperatures. No single-phase cubic zirconia was obtained with these dopants. In contrast, zirconia solid solutions with oversized dopants are very stable and both cubic and tetragonal forms can be readily obtained. This seems reasonable since $\mathrm{Fe}_{2} \mathrm{O}_{3}$ and $\mathrm{Ga}_{2} \mathrm{O}_{3}$ belong to structural types much different from the fluorite type adopted by zirconia, whereas $\mathrm{Y}_{2} \mathrm{O}_{3}$ and $\mathrm{Gd}_{2} \mathrm{O}_{3}$ have structures very similar to fluorite.

\section{(2) X-ray Absorption Spectra at the Zr-K Edge}

Representative $\mathrm{Zr}$ EXAFS data and their corresponding FT for pure zirconia and stabilized zirconia are shown in Figs. 2 and 3 . We have previously shown that the characteristic features of the zirconia EXAFS and FT are phase-dependent but dopant-independent in terms of bond length and coordination number. ${ }^{6,7}$ The spectra in Figs. 2 and 3 have the same features and are very similar to those reported in Refs. 6 and 7. These characteristic spectra allow unambiguous phase identification in single-phase materials. This is important when the crystallite sizes are so small that severe peak broadening occurs in XRD, as in the cases of $3 \mathrm{Fe} 06$ and $3 \mathrm{Ga08}$.

The first peak in the FT corresponds to the nearest neighbors (NN) of $\mathrm{Zr}$, i.e., a $\mathrm{Zr}-\mathrm{O}$ shell in these structures. The second peak in the FT corresponds to the next nearest neighbors ( $N N N$ ), i.e., a $\mathrm{Zr}$-cation shell where the cations can be either $\mathrm{Zr}$ or the dopant. Quantitative curve fitting was performed independently on Fourier-filtered first- and second-shell data. The results are given in Table III.

All of the tetragonal samples have $\mathrm{Zr}-\mathrm{O}$ bond lengths of 2.10 to $2.11 \AA$ with a coordination number of around 4 and a $\mathrm{Zr}-$ cation distance of 3.62 to $3.63 \AA$ with a coordination number of 12 . For cubic zirconia samples, the $\mathrm{Zr}-\mathrm{O}$ bond length increases to $2.15 \AA$ with 7 -fold coordination and the $\mathrm{Zr}$-cation bond length decreases to between 3.58 and $3.60 \AA$ with 12 -fold coordination. A similar structure is found for Fe- and Ga-doped monoclinic zirconia, with a $\mathrm{Zr}-\mathrm{O}$ bond length of ca. $2.15 \AA$ and a coordination number of $\approx 7$. The doped monoclinic zirconia has

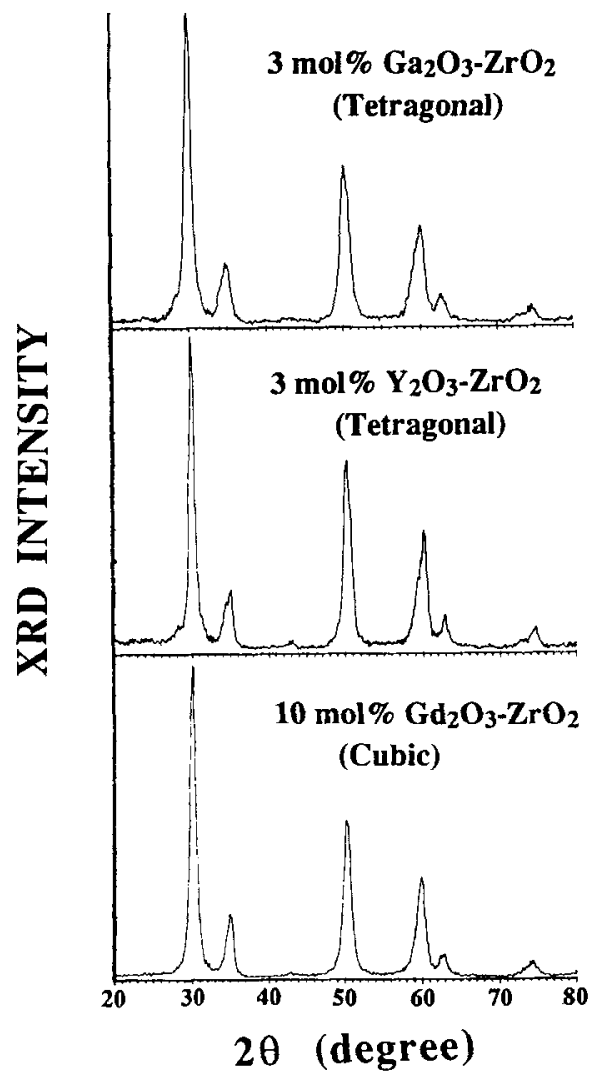

Fig. 1. X-ray diffraction patterns for three zirconia solid solutions calcined at $850^{\circ} \mathrm{C}$ 


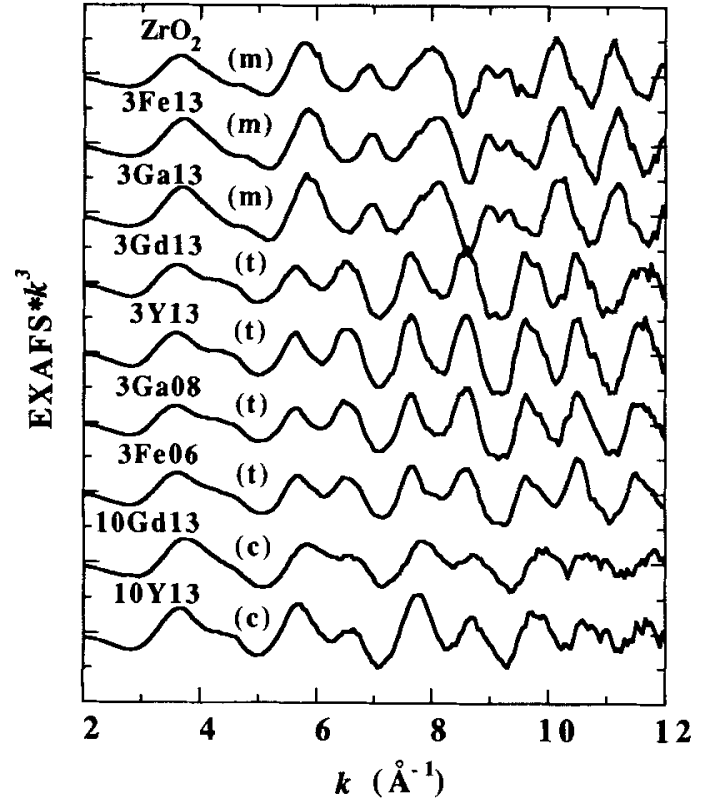

Fig. 2. $k^{3}$ weighted EXAFS spectra at $\mathrm{Zr}-K$ edge for pure and doped zirconia. Phases indicated in parentheses.

a complicated $\mathrm{Zr}$-cation shell, which is similar to that in pure $m-\mathrm{ZrO}_{2}{ }^{6}$ These structural parameters are phase-dependent and dopant-independent, confirming again that a set of characteristic structures exists for each of zirconia phases. Note that the $\mathrm{Zr}-\mathrm{O}$ shell in the tetragonal structures has a surprisingly low coordination number. As we have shown previously using lowtemperature measurements, the $\mathrm{Zr}-\mathrm{O}$ shell in tetragonal zirconia is split into two subshells and the room-temperature $\mathrm{Zr}-\mathrm{O}$ data in Table III correspond to the inner subshell only. ${ }^{6-8}$ The absence of a distinct outer subshell is mainly due to the larger disorder of these longer and looser $\mathrm{Zr}-\mathrm{O}$ bonds at room temperature. (A shorter $k$ range was used in the present study which has also reduced the resolution somewhat.)

Further information on $\mathrm{Zr}-\mathrm{O}$ and $\mathrm{Zr}$-cation bonding is contained in the Debye-Waller factor $\Delta \sigma^{2}$ (relative bond dispersion with reference to the model compound) and $\sigma^{2}$ (absolute bond dispersion). All of the tetragonal and cubic phases have a negative $\Delta \sigma^{2}$ for the $\mathrm{Zr}-\mathrm{O}$ shell. This indicates that the dispersion of the four inner $\mathrm{Zr}-\mathrm{O}$ bonds in tetragonal zirconia and the seven $\mathrm{Zr}-\mathrm{O}$ bonds in cubic zirconia is smaller than that of the seven $\mathrm{Zr}-\mathrm{O}$ bonds in $m-\mathrm{ZrO}_{2}$, used as the model compound. This is not surprising in view of the large bond length dispersion in $m-\mathrm{ZrO}_{2}$ (Table II). For the $\mathrm{Zr}$-cation shell, the $\sigma^{2}$ values generally increase as the size difference between $\mathrm{Zr}$ and the dopant cation increases and as the dopant concentration increases. This correlation suggests that the size mismatch between the host and dopant cations determines the distortion of the $\mathrm{Zr}$ network.

The $\mathrm{Zr}-K$ edge XANES spectra for the three polymorphs are shown in Figs. 4(a-c). They are characteristic of these polymorphs in that different dopant solid solutions give essentially the same spectrum as long as they are of the same phase. This confirms again that the local atomic and electronic structures of $\mathrm{Zr}$ in zirconia polymorphs are phase-dependent but dopantindependent.

\section{(3) X-ray Absorption Spectra of Dopants}

(A) $G d-L_{m}$ Edge Measurements: The EXAFS spectra at the Gd- $L_{1 t 1}$ edge for Gd-stabilized tetragonal and cubic zirconia and for pure $\mathrm{Gd}_{2} \mathrm{O}_{3}$ are shown in Fig. 5(a). The spectra for tetragonal and cubic zirconia are very similar but different from that for $\mathrm{Gd}_{2} \mathrm{O}_{3}$. The corresponding FTs shown in Fig. 5(b) have a broad $\mathrm{Gd}-\mathrm{O}$ shell as the first peak with a low amplitude for the tetragonal and cubic zirconia structures compared to the slightly
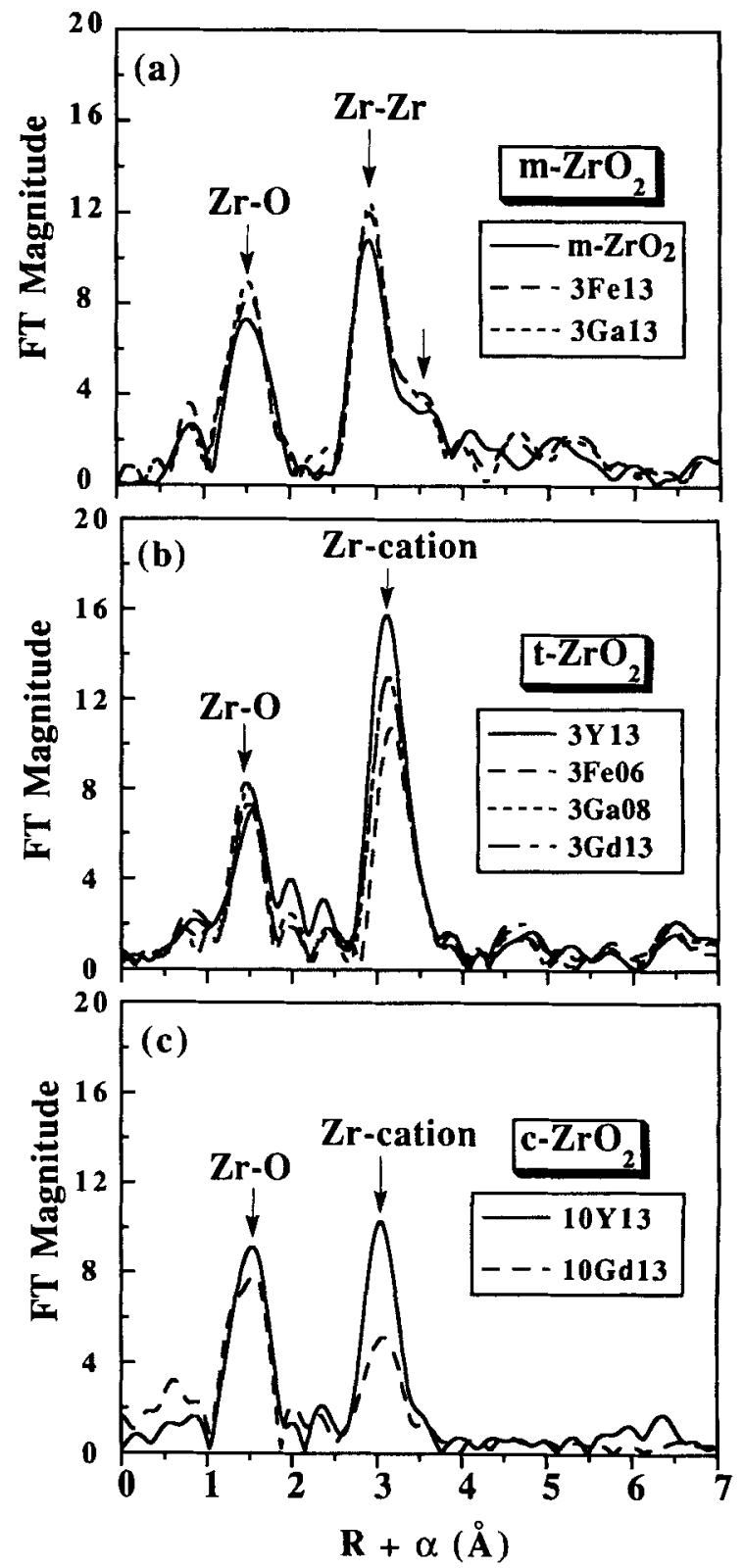

Fig. 3. Fourier transforms of $\mathrm{Zr}$ EXAFS in Fig. $2(k=3.2-$ $\left.12.0 \AA^{-1}\right)$.

stronger and sharper first peak for pure $\mathrm{Gd}_{2} \mathrm{O}_{3}$. The second peak, corresponding to the Gd-cation shell, is shorter for zirconia relative to $\mathrm{Gd}_{2} \mathrm{O}_{3}$.

Quantitative analysis of the Gd-O shell utilized the amplitude and phase functions obtained from the $\mathrm{Gd}-\mathrm{O}$ shell in $\mathrm{Gd}_{2} \mathrm{O}_{3}$. The average distance of $\mathrm{Gd}-\mathrm{O}(2.34 \AA)$ was calculated from the measured lattice parameter of $\mathrm{Gd}_{2} \mathrm{O}_{3}$ assuming an ideal C-type structure (Table II). This value and an oxygen coordination number of 6 were used to define the amplitude and phase functions. The curve-fitting parameters for Gd-doped zirconia are given in Table IV. The same $\mathrm{Gd}-\mathrm{O}$ bond length of $2.38 \AA$ obtains in both 3-mol\%-Gd-doped tetragonal zirconia and $10-\mathrm{mol} \%$-Gd-doped cubic zirconia. This is larger than the $\mathrm{Gd}-\mathrm{O}$ distance in $\mathrm{Gd}_{2} \mathrm{O}_{3}$. Since the accuracy of bond distance is very $\operatorname{good}( \pm 0.02 \AA)$ in EXAFS data, this increase provides direct evidence for a larger ionic radius for $\mathrm{Gd}^{3+}$ in the stabilized zirconia than in $\mathrm{Gd}_{2} \mathrm{O}_{3}$. The increased ionic size is consistent with an increase in coordination number, which is confirmed by the fitting results. The positive $\Delta \sigma^{2}$ values in Table IV indicate an increased distortion in the $\mathrm{Gd}-\mathrm{O}$ shell in zirconia compared to $\mathrm{C}$-type $\mathrm{Gd}_{2} \mathrm{O}_{3}$. The value is higher for the 

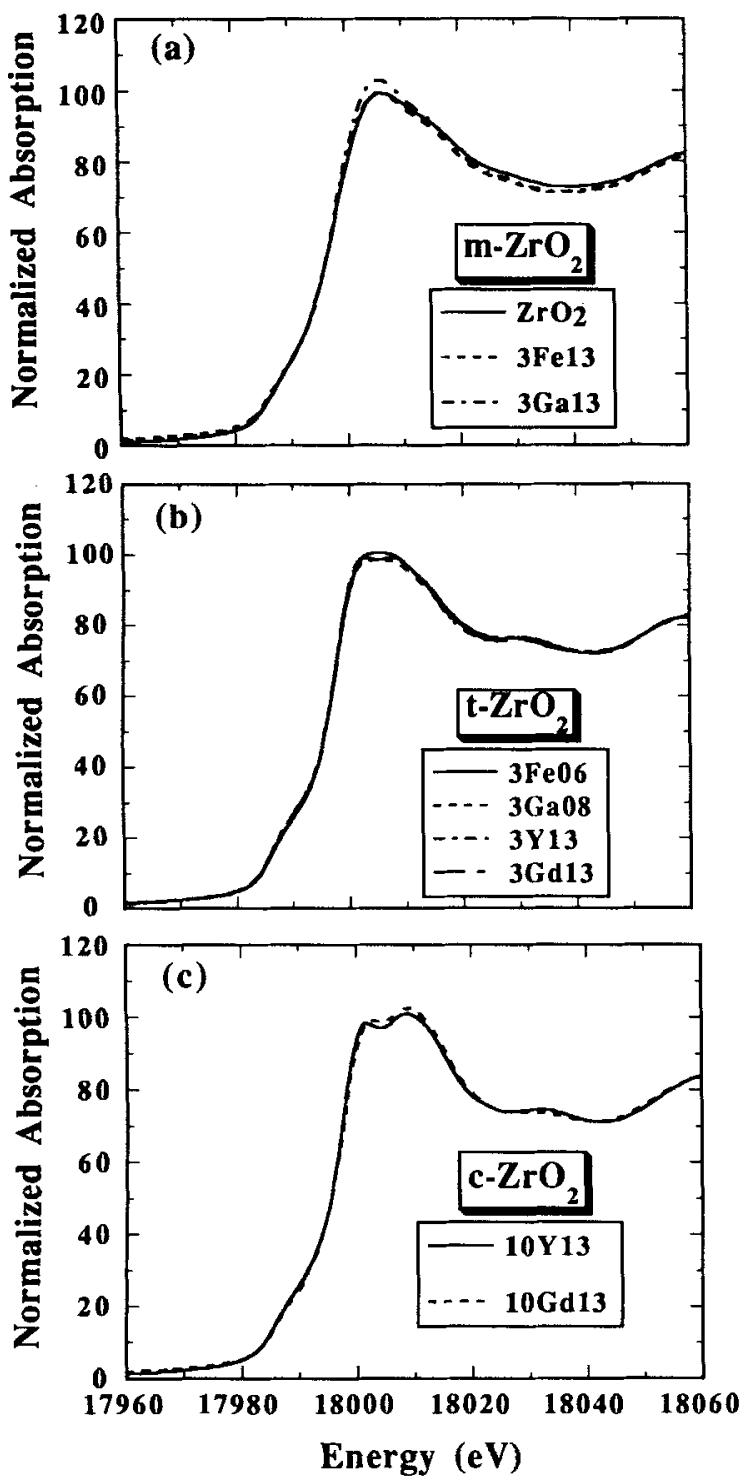

Fig. 4. XANES spectra at $\mathrm{Zr}-K$ edge for pure and trivalently doped zirconia.

$10 \mathrm{~mol} \% \mathrm{Gd}_{2} \mathrm{O}_{3}$ sample than for the $3 \mathrm{~mol} \% \mathrm{Gd}_{2} \mathrm{O}_{3}$ sample. Since the $\mathrm{Gd}-\mathrm{O}$ structure is apparently similar in both, the larger $\Delta \sigma^{2}$ indicates a greater bond length dispersion, reflecting dopant interactions.

The second peak occurs at shorter distance in Gd-stabilized zirconia than in $\mathrm{Gd}_{2} \mathrm{O}_{3}$. Theoretical amplitude and phase func- tions for $\mathrm{Gd}-\mathrm{Zr}$ were calculated using a distance of $3.620 \AA$ to fit the Gd-cation peak in both tetragonal and cubic zirconia, and the results are given in Table V. The Gd-cation distance in both zirconia is $3.62 \AA$, with a coordination number of 12 . These values are almost the same as those for the $\mathrm{Zr}$-cation shell in the corresponding samples, suggesting that $\mathrm{Gd}$ substitutes for $\mathrm{Zr}$ in the host cation network. Again, the Debye-Waller factor increases when the concentration of $\mathrm{Gd}_{2} \mathrm{O}_{3}$ increases from 3 to $10 \mathrm{~mol} \%$. This may be due either to a greater structural distortion or, alternatively, to chemical disorder as a result of mixing different amplitude and phase functions of $\mathrm{Gd}$ and $\mathrm{Zr}$ scatterers. However, both the absolute magnitude of these disorders and the rate of increase with dopant concentration are smaller than those at the $\mathrm{Zr}$ edge.

The XANES spectra at the $\mathrm{Gd}-L_{\mathrm{III}}$ edge for pure $\mathrm{Gd}_{2} \mathrm{O}_{3}$, Gd-stabilized tetragonal zirconia, and cubic zirconia are shown in Fig. 6(a). All three spectra show a strong white line. The spectra for tetragonal and cubic zirconia are nearly identical but different from that for pure $\mathrm{Gd}_{2} \mathrm{O}_{3}$. The stronger, narrower peak for Gd in zirconia suggests a less covalent environment; this is consistent with the increased bond length and coordination number.

Overall, the local structure of $\mathrm{Gd}^{3+}$ in both tetragonal and cubic zirconia closely resembles that of the host $\mathrm{Zr}$ ion, and is significantly different from that of $\mathrm{Gd}$ in $\mathrm{Gd}_{2} \mathrm{O}_{3}$. Very little distinction can be made between Gd spectra for Gd-doped tetragonal and cubic zirconia, other than a tendency for a higher Debye-Waller factor in the latter which has a higher dopant concentration.

(B) $Y$-K Edge Measurements: The EXAFS data and the corresponding FTs at the $\mathrm{Y}-K$ edge of $Y$-stabilized tetragonal and cubic zirconia and pure $\mathrm{Y}_{2} \mathrm{O}_{3}$ are shown in Figs. 7(a) and (b). As at the Gd- $L_{\text {III }}$ edge, the Y EXAFS spectra and the FTs for tetragonal and cubic zirconia are very similar, but are different from those for $\mathrm{Y}_{2} \mathrm{O}_{3}$. Only two distinct peaks, attributable to $\mathrm{Y}-\mathrm{O}$ and $\mathrm{Y}-$ cation scattering, respectively, are seen in the FTs for tetragonal and cubic zirconia. This is in contrast to the case of $\mathrm{Y}_{2} \mathrm{O}_{3}$, which has not only a $\mathrm{Y}-\mathrm{O}$ first shell but also two $\mathrm{Y}-\mathrm{Y}$ subshells. The third peak in Fig. 7(b) may be attributed to the outer $\mathrm{Y}-\mathrm{Y}$ subshell plus some outer $\mathrm{Y}$-O based on the crystallographic data for $\mathrm{Y}_{2} \mathrm{O}_{3}$ (Ref. 32). The $\mathrm{Y}$-cation distance in stabilized zirconia is larger than the inner $Y-Y$ subshell but smaller than the outer $\mathrm{Y}-\mathrm{Y}$ subshell in $\mathrm{Y}_{2} \mathrm{O}_{3}$.

Quantitative structural information for the $\mathrm{Y}-\mathrm{O}$ shell was obtained by curve fitting using amplitude and phase functions derived from pure $\mathrm{Y}_{2} \mathrm{O}_{3}$. The results are given in Table IV. The $\mathrm{Y}-\mathrm{O}$ bond distance for both 3 and $10 \mathrm{~mol} \% \mathrm{Y}_{2} \mathrm{O}_{3}-\mathrm{ZrO}_{2}$ samples is $2.33 \AA, 0.05 \AA$ longer than that in $\mathrm{Y}_{2} \mathrm{O}_{3}$. As with $\mathrm{Gd}$, this increase is probably due to an increase in $\mathrm{Y}-\mathrm{O}$ coordination number in $\mathrm{Y}$-doped zirconia $(\mathrm{CN}=8)$ relative to $\mathrm{Y}_{2} \mathrm{O}_{3}(\mathrm{CN}=$ 6). Again, positive $\Delta \sigma^{2}$ values were obtained for the $Y-O$ shell in both the tetragonal and cubic zirconia structures, indicating
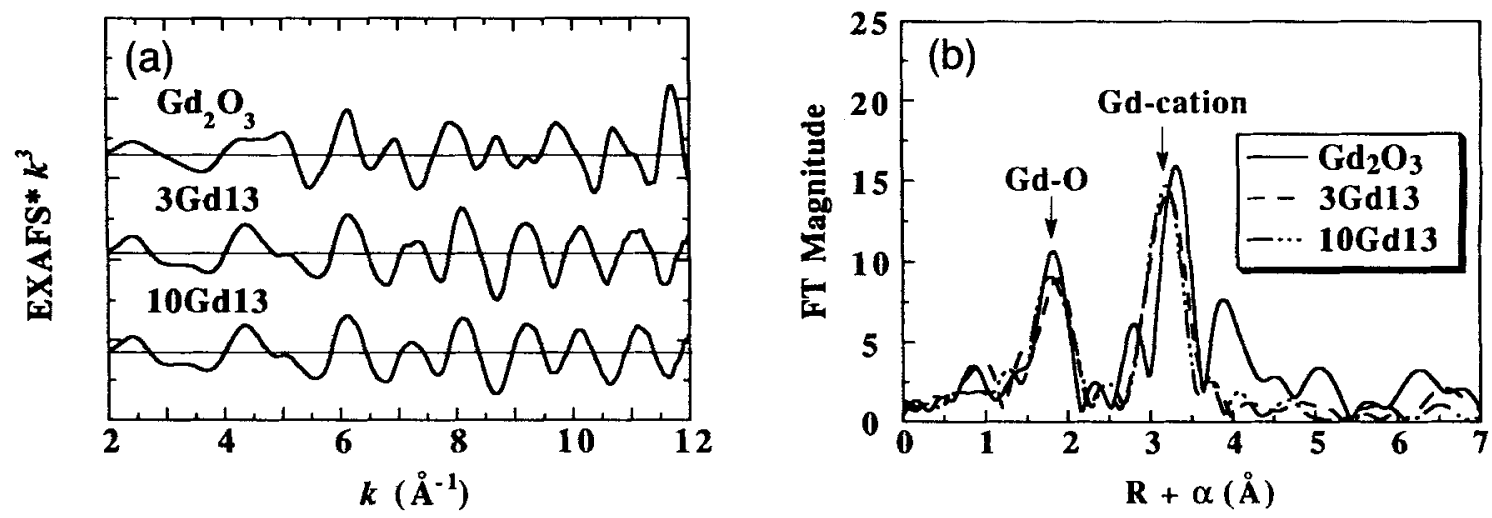

Fig. 5. (a) $k^{3}$ weighted EXAFS spectra at Gd- $L_{\mathrm{III}}$ edge for Gd-doped zirconia and pure $\mathrm{Gd}_{2} \mathrm{O}_{3}$. (b) Fourier transforms of $\mathrm{Gd}$ data in (a) $(k=$ $\left.2.0-12.5 \AA^{-1}\right)$. 

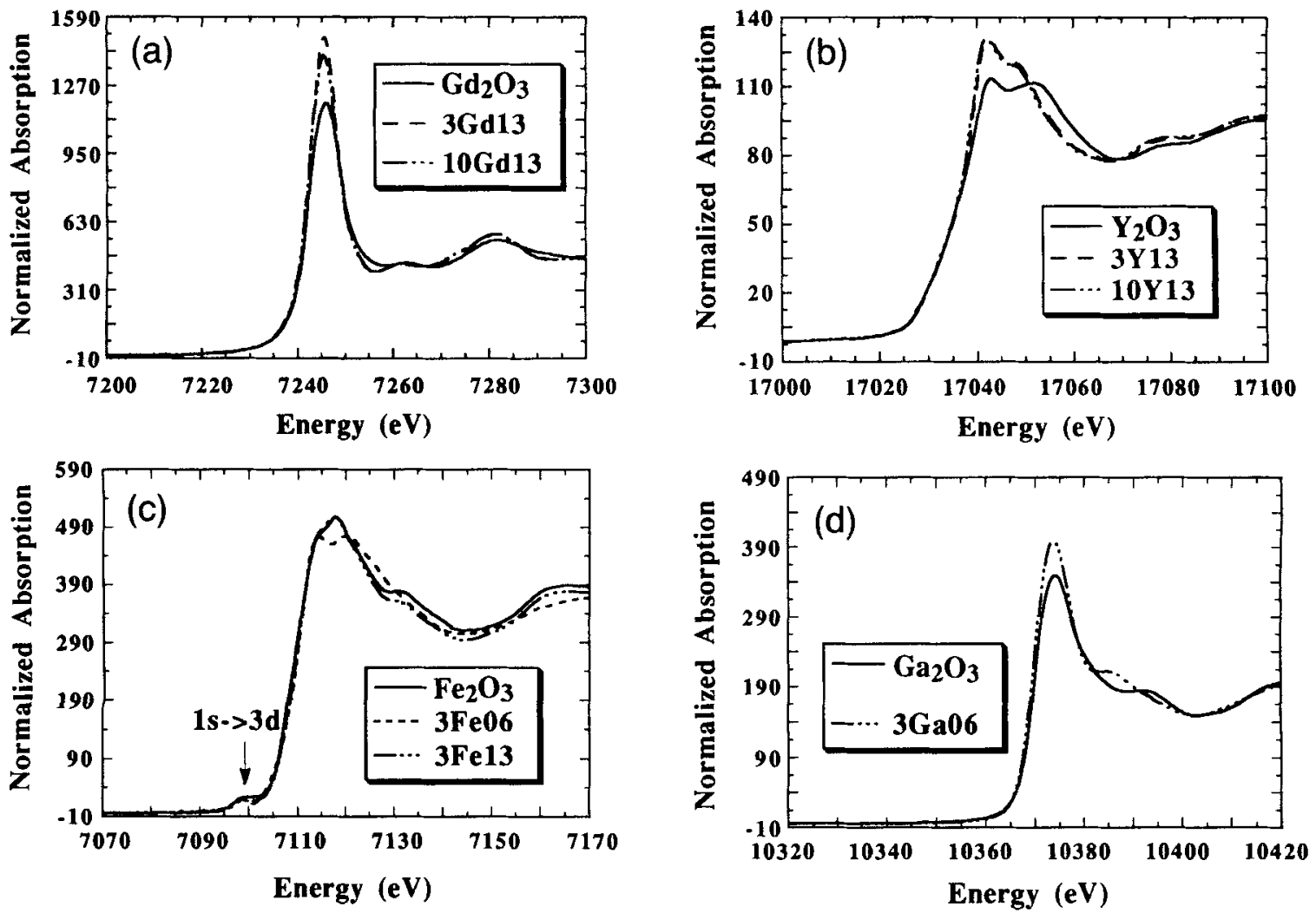

Fig. 6. XANES spectra (a) at $\mathrm{Gd}-L_{\mathrm{III}}$ edge for Gd-doped zirconia and pure $\mathrm{Gd}_{2} \mathrm{O}_{3}$. (b) at $\mathrm{Y}-\mathrm{K}$ edge for $\mathrm{Y}$-doped zirconia and pure $\mathrm{Y}_{2} \mathrm{O}_{3}$. (c) at $\mathrm{Fe}-\mathrm{K}$ edge for Fe-doped zirconia and pure $\mathrm{Fe}_{2} \mathrm{O}_{3}$. (d) at $\mathrm{Ga}-\mathrm{K}$ edge for $\mathrm{Ga}$-doped zirconia and pure $\mathrm{Ga}_{2} \mathrm{O}_{3}$.
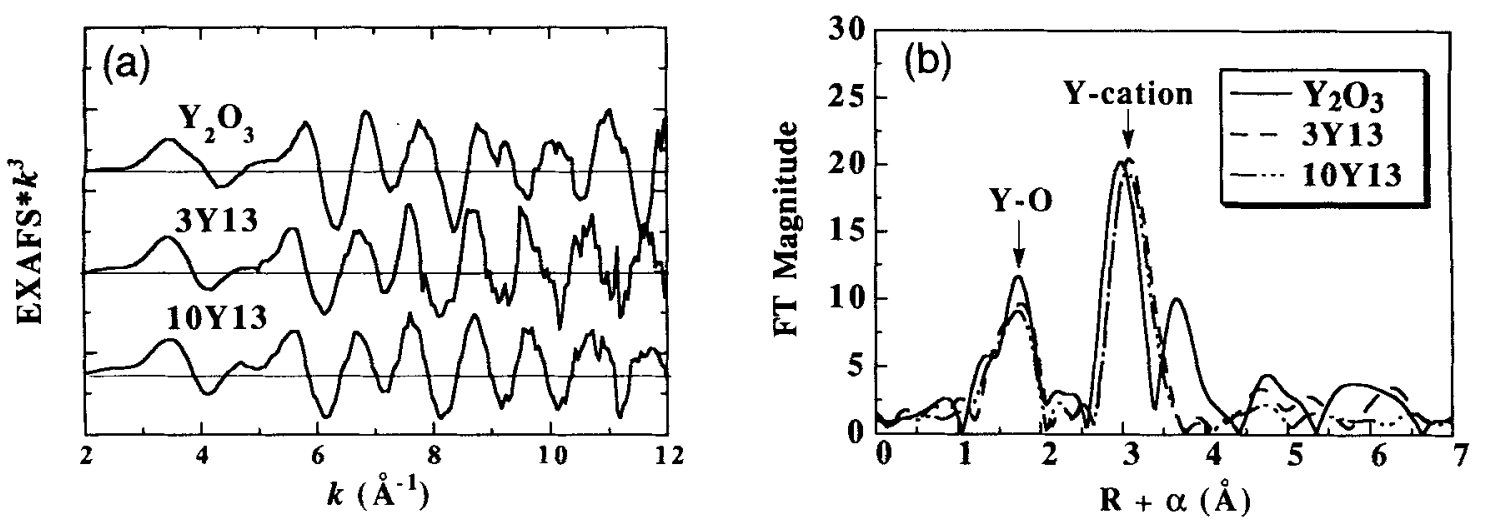

Fig. 7. (a) $k^{3}$ weighted EXAFS spectra at $\mathrm{Y}$ - $K$ edge for $\mathrm{Y}$-doped zirconia and pure $\mathrm{Y}_{2} \mathrm{O}_{3}$. (b) Fourier transforms of $\mathrm{Y}$ data in (a) $\left(k=3.2-11.8 \AA^{-1}\right)$.

increased bond dispersions relative to $\mathrm{Y}_{2} \mathrm{O}_{3}$. All of these observations are similar to those for Gd doping.

The second shell (Y-cation) was fitted using the theoretical amplitude and phase functions for $\mathrm{Y}-\mathrm{Zr}$, with a distance of $3.620 \AA$. As before, the bond length ( $3.62 \AA$ ) and coordination number (12) for both samples are identical to those for the $\mathrm{Zr}$ cation shell in the zirconia matrix, but different from those for $\mathrm{Y}-\mathrm{Y}$ in $\mathrm{Y}_{2} \mathrm{O}_{3}$. This again suggests that $\mathrm{Y}$ substitutes for $\mathrm{Zr}$ in the host $\mathrm{Zr}-\mathrm{Zr}$ network in stabilized zirconia. As with Gd doping, a slight increase in dispersion for the second shell is seen for the higher $Y$ concentration sample. Since chemical disorder is not significant in view of the nearly identical scattering function of $\mathrm{Y}$ and $\mathrm{Zr}$, the increase in Debye-Waller factor must be caused by an increase in distortion of $\mathrm{Y}$-centered cation network. Comparing $\mathrm{Y}$ and $\mathrm{Gd}$ doping, we note that the DebyeWaller factor is smaller for $\mathrm{Y}$ - than Gd-doped samples. This is consistent with their respective size misfit relative to $\mathrm{Zr}$.
The Y near-edge data, shown in Fig. 6(b), are similar for tetragonal and cubic zirconia but different from that for $\mathrm{Y}_{2} \mathrm{O}_{3}$. As with Gd, the main peak is stronger and narrower for the doped samples than for the pure oxide. As in the case of Gd doping, both the EXAFS and XANES data suggest that the local structure of $Y$ in tetragonal and cubic zirconia bears more similarity to that of $\mathrm{Zr}$ in zirconia than that of $\mathrm{Y}$ in $\mathrm{Y}_{2} \mathrm{O}_{3}$. These results support the physical picture of $\mathrm{Ho}^{9}$ for oversized trivalent dopants. Essentially in the stabilized zirconia, the smaller $\mathrm{Zr}$ find it difficult to assume the 8-fold coordination which is ideal for the fluorite structure, while the oversized stabilizers can adopt 8-fold coordination but they must abandon their parent structures (C-type $\mathrm{Y}_{2} \mathrm{O}_{3}$ or $\mathrm{Gd}_{2} \mathrm{O}_{3}$ in 6-fold coordination). This applies for both tetragonal and cubic phases, and results in an increase in the dopant- $\mathrm{O}$ bond distance. Beyond the first shell, there is only a small distortion in the dopant-substituted $\mathrm{Zr}$ network. The distortion increases as the dopant concentration increases and as the size misfit increases. 

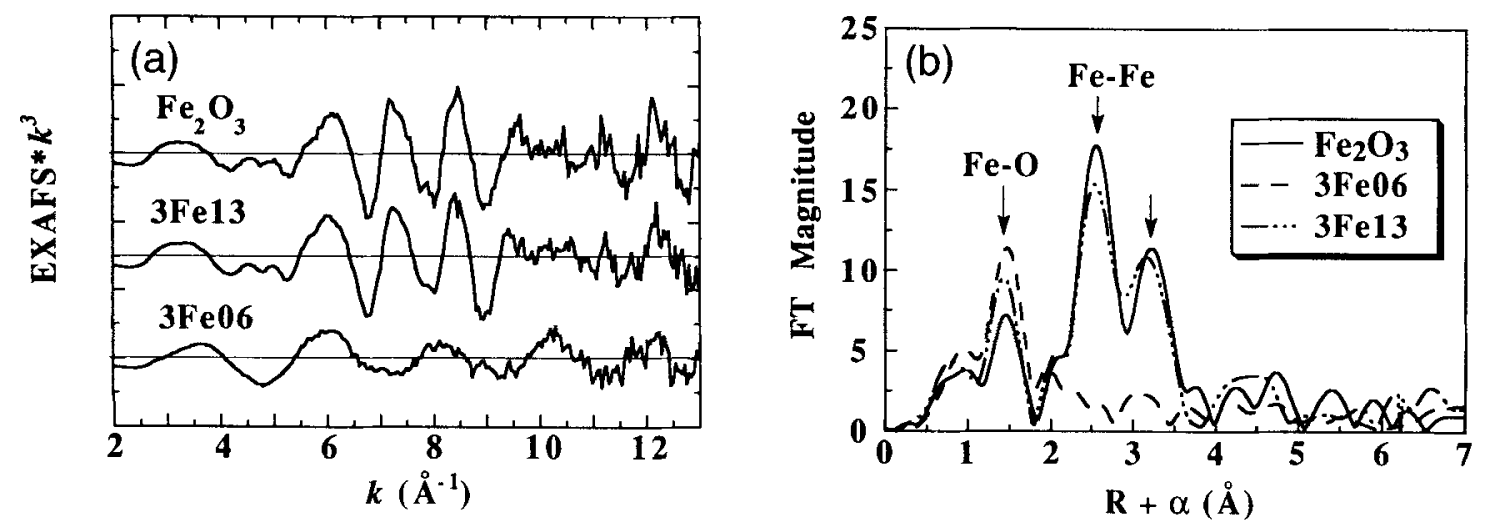

Fig. 8. (a) $k^{3}$ weighted EXAFS spectra at $\mathrm{Fe}-K$ edge for Fe-doped zirconia and pure $\mathrm{Fe}_{2} \mathrm{O}_{3}$. (b) Fourier transforms of $\mathrm{Fe}$ data in (a) $(k=$ $3.0-12.5 \AA^{-1}$ ).

(C) Fe-K Edge Measurements: Both $\mathrm{Fe}_{2} \mathrm{O}_{3}$ and monoclinic zirconia were observed in $3-\mathrm{mol} \%-\mathrm{Fe}_{2} \mathrm{O}_{3}$-doped zirconia calcined at $1300^{\circ} \mathrm{C}$, while tetragonal zirconia seemed to be dominant when calcined at $650^{\circ} \mathrm{C}$. The EXAFS data and the corresponding FT at the $\mathrm{Fe}-\mathrm{K}$ edge for pure $\mathrm{Fe}_{2} \mathrm{O}_{3}$ and the two doped samples are shown in Figs. 8(a) and (b). It is apparent that the EXAFS and FT for the high-temperature calcined powder are very similar to those for pure $\mathrm{Fe}_{2} \mathrm{O}_{3}$. This indicates that $\mathrm{Fe}_{2} \mathrm{O}_{3}$ has precipitated from the zirconia matrix at $1300^{\circ} \mathrm{C}$, leaving unstabilized zirconia which transforms to the monoclinic form during cooling. This is not the case for the low-temperature calcined powders. Here the Fe has its unique EXAFS and FT spectra (Figs. 8(a) and (b)), the Zr EXAFS is characteristic of the tetragonal local structure (Fig. 2), and the XRD is consistent with a tetragonal phase. The distinct $F e$ spectra rule out the possibility of significant $\mathrm{Fe}_{2} \mathrm{O}_{3}$ separation from $\mathrm{ZrO}_{2}$ in $3 \mathrm{Fe} 06$; i.e., a tetragonal solid solution must have formed.

Quantitative results for the local structures of $\mathrm{Fe}$ in $3 \mathrm{Fe} 06$ and $3 \mathrm{Fe} 13$ were obtained using $\mathrm{Fe}_{2} \mathrm{O}_{3}$ as a model. For both samples, the $\mathrm{Fe}-\mathrm{O}$ bond distance is very close to that in $\mathrm{Fe}_{2} \mathrm{O}_{3}$. This is not surprising for the high-temperature calcined sample which appears to contain primarily $\mathrm{Fe}_{2} \mathrm{O}_{3}$. However, the similarity in $\mathrm{Fe}-\mathrm{O}$ bond length for $3 \mathrm{Fe} 06$ and $\mathrm{Fe}_{2} \mathrm{O}_{3}$ is quite different from the results for oversized dopants. This suggests that the $\mathrm{Fe}-\mathrm{O}$ coordination in the stabilized zirconia is similar to that in $\mathrm{Fe}_{2} \mathrm{O}_{3}$, maintaining 6-fold coordination. Also unexpected is the absence of a second-shell peak attributable to Fe-cation scattering. This suggests an unusually broad length dispersion of next nearest neighbors around the undersized $\mathrm{Fe}$ in the fluorite-like matrix.

The Fe XANES spectra for these samples are shown in Fig. 6(c). The almost identical spectra for pure $\mathrm{Fe}_{2} \mathrm{O}_{3}$ and $3 \mathrm{Fe} 13$ are again consistent with $\mathrm{Fe}$ being present primarily as $\mathrm{Fe}_{2} \mathrm{O}_{3}$. The unique spectrum for $\mathrm{Fe}$ in $3 \mathrm{Fe} 06$, on the other hand, points to a difference between the local structures of $\mathrm{Fe}$ in doped zirconia and its parent oxide. Note that the pre-edge peak for Fe is due to a $1 s \rightarrow 3 d$ transition. ${ }^{33}$ This transition is forbidden by dipole selection rules for centrosymmetric complexes, although it is always present as a weak transition due to direct electric quadrupole coupling. ${ }^{34}$ The $1 s \rightarrow 3 d$ transition becomes partially dipole-allowed in noncentrosymmetric complexes due to $d-p$ orbital mixing. The concomitant increase in $1 s \rightarrow 3 d$ intensity can be used to probe the symmetry of the absorber. ${ }^{33}$ The $1 \mathrm{~s} \longrightarrow$ $3 d$ transitions for $\mathrm{Fe}$ in $3 \mathrm{Fe} 06$ and $3 \mathrm{Fe} 13$ are highlighted in the insets of Fig. 9. These were calculated by subtracting an arctangent function from the XANES data. The normalized area of this peak is 15.2 for $3 \mathrm{Fe} 06,14.4$ for $3 \mathrm{Fe} 13$, and 16.3 for $\mathrm{Fe}_{2} \mathrm{O}_{3}$, in units of $10^{-2} \mathrm{eV}$. These values are consistent with those for 5 -coordinated structures in Fe-containing proteins reported by Roe et al. ${ }^{33}$ Since $\mathrm{Fe}_{2} \mathrm{O}_{3}$ is known to have an octahedral coordination, the same magnitude of the $1 s \rightarrow 3 d$ peak area for the other two samples suggests a similar geometry for them. The fact that the $1 s \rightarrow 3 d$ transition is much sharper for $3 \mathrm{Fe} 06$ than for $3 \mathrm{Fe} 13$ or $\mathrm{Fe}_{2} \mathrm{O}_{3}$ suggests a smaller spread in $\mathrm{Fe} 3 d$ orbital energies in the former. This implies a distorted, although still approximately centrosymmetric, $\mathrm{Fe}$ environment in $3 \mathrm{Fe} 06$.

Returning to the main peak, the very different shape in the XANES spectra of $3 \mathrm{Fe} 06$ compared to $3 \mathrm{Fe} 13$ or $\mathrm{Fe}_{2} \mathrm{O}_{3}$ is most likely due to a different arrangement of the Fe-cation network. This is consistent with the EXAFS results which suggest that the $\mathrm{Fe}$-cation network in 3Fe06, although highly distorted, is probably the same as the $\mathrm{Zr}-\mathrm{Zr}$ network and is fluorite-like. This is very different from the $\mathrm{Fe}-\mathrm{Fe}$ network in $\mathrm{Fe}_{2} \mathrm{O}_{3}$.

(D) Ga-K Edge Measurements: XAS measurements at the $\mathrm{Ga}-\mathrm{K}$ edge were made for pure $\mathrm{Ga}_{2} \mathrm{O}_{3}$ and for 3-mol\%$\mathrm{Ga}_{2} \mathrm{O}_{3}$-stablized zirconia calcined at $850^{\circ}$ and $1300^{\circ} \mathrm{C}(3 \mathrm{Ga} 08$ and $3 \mathrm{Ga13}$ ). According to XRD (Table I), 3Ga08 is tetragonal zirconia, while $3 \mathrm{Ga} 13$ is monoclinic zirconia. The Ga- $K$ edge
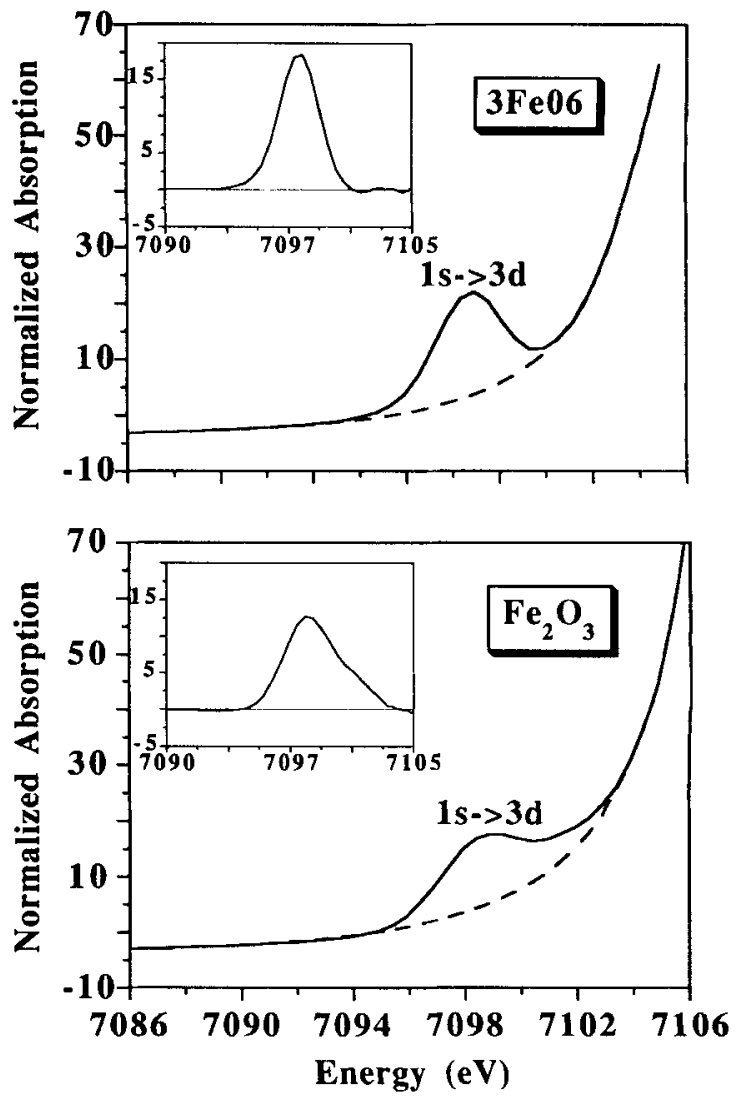

Fig. 9. X-ray absorption pre-edge structure of Fe for Fe-doped zirconia and pure $\mathrm{Fe}_{2} \mathrm{O}_{3}$. 

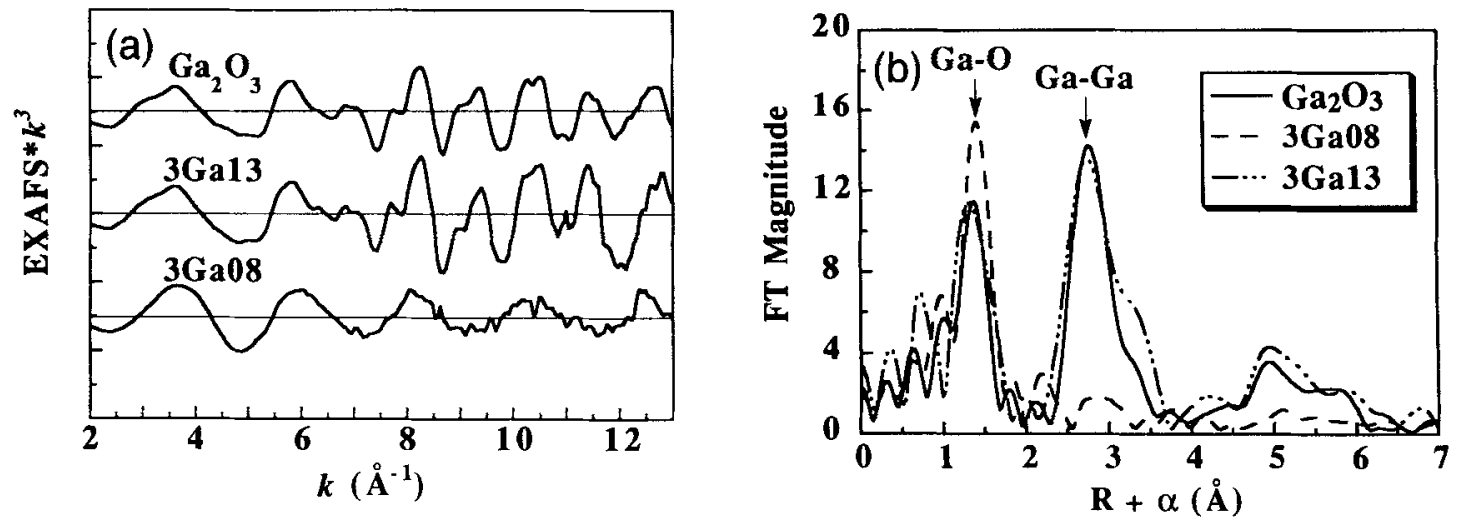

Fig. 10. (a) $k^{3}$ weighted EXAFS spectra at $\mathrm{Ga}-K$ edge for $\mathrm{Ga}$-doped zirconia and pure $\mathrm{Ga}_{2} \mathrm{O}_{3}$. (b) Fourier transforms of $\mathrm{Gd}$ data in (a) $(k=$ $\left.3.0-13.0 \AA^{-1}\right)$.

EXAFS data for these samples and the corresponding FTs are given in Figs. 10(a) and (b). Comparing these data, we find that, like the Fe case, $3 \mathrm{Ga08}$ has distinctly different EXAFS from that of $\mathrm{Ga}_{2} \mathrm{O}_{3}$, whereas $3 \mathrm{Gal} 3$ and $\mathrm{Ga}_{2} \mathrm{O}_{3}$ have very similar spectra. This, together with the XRD data, demonstrates that at $1300^{\circ} \mathrm{C} \mathrm{Ga}_{2} \mathrm{O}_{3}$ has separated from the zirconia matrix, causing the latter to transform to the monoclinic phase during cooling. As with $\mathrm{Fe}$, no detectable second-shell feature is observed in FT for $3 \mathrm{Ga08}$. For more quantitative analysis, the $\mathrm{Ga}-\mathrm{O}$ shell was fitted using amplitude and phase functions calculated from $\mathrm{Ga}_{2} \mathrm{O}_{3}$ as a model compound. The results are shown in Table III. As in the $\mathrm{ZrO}_{2}-\mathrm{Fe}_{2} \mathrm{O}_{3}$ systems, all of the $\mathrm{Ga}-\mathrm{O}$ bond lengths in the Ga-doped zirconia samples are similar to that in pure $\mathrm{Ga}_{2} \mathrm{O}_{3}$. This suggests 6-fold $\mathrm{Ga}-\mathrm{O}$ coordination in both of the doped samples. The $\mathrm{Ga}-\mathrm{O}$ shell is again accompanied by a severe distortion of the surroundings which is manifested by the loss of the second-shell peak in the FT of $3 \mathrm{Ga08}$. The above picture is exactly the same as the one we suggested for the other undersized trivalent dopant, Fe.

Figure $6(\mathrm{~d})$ shows the XANES data of $\mathrm{Ga}-\mathrm{K}$ edge in $\mathrm{Ga}_{2} \mathrm{O}_{3}$ and $3 \mathrm{Ga} 08$ samples. As with $\mathrm{Fe}$, the $3 \mathrm{Ga} 13$ edge is the same as that for $\mathrm{Ga}_{2} \mathrm{O}_{3}$ but the spectra in $3 \mathrm{Ga0} 8$ and $\mathrm{Ga}_{2} \mathrm{O}_{3}$ are different. This probably reflects the different cation lattice around $\mathrm{Ga}$, consistent with the EXAFS results. No $1 s \rightarrow 3 d$ transition is observed since $\mathrm{Ga}$ has a full $d$ shell.

\section{Discussion}

\section{(1) Dopant Size Effects}

This work has shown a clear dependence of the dopant structure on dopant size. Oversized dopants form solid solutions adopting the zirconia structure, in terms of both dopant-oxygen bond length and dopant-cation distance. The apparent ionic radii for the dopant cations are ca. 0.04 to $0.05 \AA$ larger than those in the parent oxides. This increase is much larger than the relative uncertainty of ca. 0.01 to $0.02 \AA$ of the technique. The longer bond lengths imply an increase in $\mathrm{Gd}$ and $\mathrm{Y}$ coordination numbers above the 6-fold coordination found in C-type rareearth oxides. A direct comparison of our cation-O bond lengths with Shannon's values ${ }^{37}$ would favor 7-fold coordination. However, the size-coordination correspondence is affected by polyhedral distortion, covalency, defect and electronic configurations between cation and anion, and the host matrix. Similar distances have been reported for 8-fold-coordinated $\mathrm{Y}-\mathrm{O}$ and Gd-O, e.g., in $\mathrm{YNbO}_{4}(2.32 \AA),{ }^{38}$ in $\mathrm{YTaO}_{4}(2.35 \AA),{ }^{39}$ and in $\mathrm{GdAsO}_{4}(2.38 \AA){ }^{40}$ Therefore, we suggest 8 -fold coordination for $\mathrm{Gd}$ and $\mathrm{Y}$ in zirconia solid solutions based on the EXAFS data of both host and dopant cations. (In $\mathrm{ZrO}_{2}-\mathrm{YNbO}_{4}$ solid solutions, which contain no oxygen vacancies and thus are likely to have 8-fold-coordinated Y, our EXAFS data also give a $\mathrm{Y}$-O distance of $2.32 \AA{ }^{41}$ ) Eightfold dopant coordination then leaves oxygen vacancies next to the $\mathrm{Zr}$ cations. The same conclusion has also been reached by comparing the $\mathrm{Zr}$-XANES data for $\mathrm{ZrO}_{2}-\mathrm{Y}_{2} \mathrm{O}_{3}$ solid solutions from 3 to $20 \mathrm{~mol} \% \mathrm{Y}_{2} \mathrm{O}_{3}$ and by comparing the EXAFS distortions of the cation-cation shells in the same. ${ }^{7}$ The fact that $\mathrm{Zr}$-vacancy pairing is energetically more favorable than $\mathrm{Y}$-vacancy pairing in $\mathrm{Y}$-doped zirconia has been suggested previously by computer simulations. ${ }^{42}$

On the other hand, undersized trivalent dopants, which substitute randomly for $\mathrm{Zr}$ ions and remain in zirconia solid solutions at least at low temperatures, are in 6-fold coordination and thus in competition with $\mathrm{Zr}$ ions for the oxygen vacancies. Previous studies have found that for cubic zirconia (Y-stabilized), the lattice constant decreases with the increasing content of undersized dopants $\left(\mathrm{Cr}^{3+}\right.$ or $\left.\mathrm{Fe}^{3+}\right) .^{43,44}$ The electron spin resonance, optical absorption, and emission spectra for $\mathrm{Cr}^{3+}$ in $\mathrm{Y}$ stabilized cubic zirconia single crystals also point to a solid solution with 6-fold-coordinated $\mathrm{Cr}^{45}$ The 6-fold cation-O association may be interpreted in terms of a defect model, shown in Fig. 11, in which two undersized ions are situated in neighboring cells sharing one oxygen vacancy. Inward relaxation of the neighboring oxygen ions in a trigonal distortion around the dopant ${ }^{45}$ and outward relaxation of the two body diagonal oxygen ions then leave six oxygen neighbors for each dopant cation which itself undergoes some off-centered displacement toward the vacancy.

There is additional evidence in the literature that undersized dopants favor nearest-neighbor oxygen vacancy association. For example, although solubilities of undersized dopants $\left(\mathrm{Fe}^{3+}\right.$ and $\mathrm{Cr}^{3+}$ ) are usually very low, they can be increased if free oxygen vacancies are introduced by other oversized dopants $\left(\mathrm{Y}^{3+}, \mathrm{Sc}^{3+}\right)$ in cubic zirconia solid solutions. ${ }^{43,44}$ The energetically favorable association of undersized dopants with oxygen vacancies provided by other oversized dopants, i.e., a type of

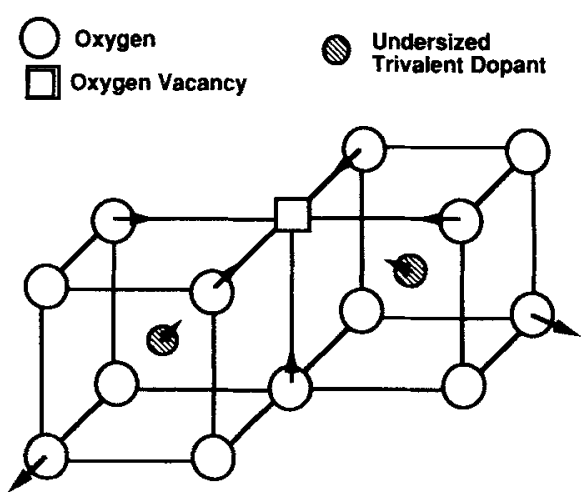

Fig. 11. Schematic diagram of vacancy-undersized dopant association and local distortion. 
scavenging effect, is apparently similar to that reported for $\mathrm{Sc}$ in $\mathrm{CeO}_{2}{ }^{46}$ This scavenging is probably also responsible for the slightly decreased ionic conductivity of $\mathrm{Y}$-stabilized zirconia when $\mathrm{Cr}^{3+}$ and $\mathrm{Fe}^{3+}$ are added. ${ }^{43,44,47}$

Taken together, we can summarize the vacancy $\left(V_{0}\right)$-cation association using a scheme outlined in Fig. 12. Here, $M$ is the trivalent dopant which can be either oversized or undersized. In the case of undersized dopant, $\mathrm{M}-V_{0}-\mathbf{M}$ association (model 1 ) is appropriate, whereas in the case of oversized dopant, only $\mathrm{Zr}-V_{0}-\mathrm{Zr}$ association is allowed (model 3). The intermediate case where $\mathrm{M}-V_{0}-\mathrm{Zr}$ (model 2) is envisioned is also included for later reference. Using this scheme, the fraction of $\mathrm{Zr}$ having $\mathrm{ZrO}_{7}$ or $\mathrm{ZrO}_{8}$ coordination can be readily calculated. ${ }^{7}$ For the same dopant composition, the fraction of $\mathrm{ZrO}_{7}$ will be twice as large with oversized dopants as it is with undersized dopants. The ratio of $\mathrm{ZrO}_{7} / \mathrm{ZrO}_{8}$ is 1 for $11 \mathrm{~mol} \% \mathrm{M}_{2} \mathrm{O}_{3}$ with oversized dopants but only reaches 1 for $20 \mathrm{~mol} \% \mathrm{M}_{2} \mathrm{O}_{3}$ with undersized dopants.

Finally, we note the apparently asymmetric response of the host cation network, i.e., very large distortion in the case of undersized dopants and much smaller distortion in the case of oversized dopants. This observation is somewhat surprising in that theoretical considerations based on continuum mechanics actually predict that the distortion of the second shell should be only $3 / 8$ of that of the first shell, and that no asymmetry should arise. $^{6}$ On the other hand, the asymmetric response could be rooted in the asymmetry of the interatomic potential, which is much stiffer in compression than in dilatation because of hardcore repulsion. Since the $\mathrm{MO}_{\mathrm{B}}$ polyhedra of the oversized dopants are in compression, the much stiffer potential that they experience results in a relatively small matrix distortion. In contrast, the $\mathrm{MO}_{6}$ polyhedra of undersized dopants are in dilatation and are capable of causing large distortions in the neighboring cation network. As will be described in subsequent publications, this asymmetry is a general feature for other dopants of different sizes in zirconia solid solutions, and can be more quantitatively understood using model calculations employing anharmonic interatomic potentials.

\section{(2) Stabilization Process}

The tetragonal-to-cubic transformation in zirconia solid solutions involves distortion of the nearest-neighbor $\mathrm{Zr}-\mathrm{O}$ shell. Since fully stabilized cubic zirconia solid solutions have 7 -fold $\mathrm{Zr}-\mathrm{O}$ coordination, oxygen vacancies associated with $\mathrm{Zr}$ ions can obviously facilitate the transformation. Stabilization of the cubic phase occurs when oversized trivalent dopants are added to zirconia in sufficient quantity. The simple model of $\mathrm{Ho}^{9}$ gives the minimum concentration required for stabilization as 11 mol\% $\mathrm{M}_{2} \mathrm{O}_{3}$ since at this concentration $\mathrm{Zr}$ is as likely to be in $7-$ fold coordination as in 8 -fold coordination (i.e., $\mathrm{ZrO}_{7} / \mathrm{ZrO}_{8}=1$ in model 3 of Fig. 12) if all of the oxygen vacancies are released from oversized cation dopants. Our data show that this model is applicable to oversized dopants. Our data also suggest that formation of a cubic phase with under-sized dopants should be twice as difficult, since half as many free oxygen vacancies are available for $\mathrm{Zr}$ association. This is consistent with our experience that it is difficult to form cubic solid solutions of undersized trivalent dopants. The very severe distortion of the undersized dopant-substituted $\mathrm{Zr}$ network probably further limits the solubility of these dopants in tetragonal and cubic zirconia.

The tetragonal-to-monoclinic transformation requires distortion of both the nearest-neighbor $\mathrm{Zr}-\mathrm{O}$ shell and the nextnearest-neighbor $\mathrm{Zr}-\mathrm{Zr}$ shell. ${ }^{6}$ The mere presence of $\mathrm{ZrO}_{7}$ does not facilitate the transformation; it actually decreases the driving force and provides partial stabilization. We have found that both undersized and oversized trivalent dopants are capable of stabilizing the tetragonal phase against monoclinic distortion. Other evidence that undersized trivalent dopants stabilize tetragonal zirconia includes DTA measurements of Kiminami ${ }^{48}$ using $\mathrm{Fe}^{3+}$ as a stabilizer. The stability of tetragonal zirconia with undersized dopants is apparently lower than that with oversized dopants.

The difference can once again be explained by the different fraction of $\mathrm{ZrO}_{7}$ available at a given concentration of oversized and undersized trivalent dopants. We have shown in a study of the temperature dependence of $\mathrm{EXAFS}^{8}$ that the similar fcc cation network is more stable against thermal distortion in the stabilized cubic phase than in the tetragonal phase, with the principal structural difference being that cubic phase has more $\mathrm{ZrO}_{7}$ than the tetragonal phase. Since crystallographically a decrease of tetragonality is observed with increasing $\mathrm{ZrO}_{7}$ concentrations, the loss of tetragonality is thus correlated with increasing stability against monoclinic distortion. Indeed, all of the oversized trivalent dopants have the same concentration dependence in their effect on tetragonality, and all have the same tetragonal/monoclinic $(t / m)$ boundary, whereas undersized trivalent dopants have less effect on tetragonality and have a higher $t / m$ boundary. ${ }^{49}$ Lefèvre' and Sheu et al..$^{5}$ have pointed out that the tetragonality vanishes at a unique composition of $10 \mathrm{~mol} \% \mathrm{M}_{2} \mathrm{O}_{3}$ for oversized trivalent dopants. This is quite close to the composition when $\mathrm{ZrO}_{7} / \mathrm{ZrO}_{8}$ equals unity ( 11 mol\% $\mathrm{M}_{2} \mathrm{O}_{3}$ ). Inasmuch as undersized trivalent dopants provide only half as many $\mathrm{ZrO}_{7}$ for the same dopant content, the resultant stabilization and tetragonality reduction should be only about half as large.

It is conceivable that trivalent dopants which have ionic radii comparable to that of $\mathrm{Zr}$ will compete with $\mathrm{Zr}$ for vacancies. We have considered such a model in Fig. 12 (model 2) with only one trivalent dopant as nearest-neighbor to the oxygen vacancy $\left(\mathrm{M}-V_{0}-\mathrm{Zr}\right)$. The calculated $\mathrm{ZrO}_{7} / \mathrm{ZrO}_{8}$ ratio is intermediate between model allowing $\mathrm{M}-V_{0}-\mathrm{M}$ association and model having $\mathrm{Zr}-V_{0}-\mathrm{Zr}$ association only. ${ }^{7}$ We believe such a case actually exists for Sc-doped $\mathrm{ZrO}_{2}$. Sc doping does form cubic zirconia and is more effective than $\mathrm{Fe}$ and $\mathrm{Ga}$ in stabilizing tetragonal zirconia. However, for a given dopant concentration, the decrease in tetragonality with increasing Sc concentration is smaller than that for oversized trivalent dopants, and the stability boundaries between $t$ and $c$ and between $t$ and $m$ phases are higher than for oversized dopants. ${ }^{49}$ Indeed, the $t / c$ boundary
$\mathrm{Zr}^{4+} \mathrm{M}^{3+}$

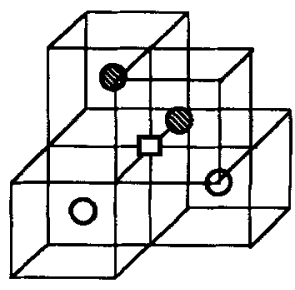

Model 1: $\mathbf{M} \cdot \mathbf{V}_{\mathbf{0}}-\mathbf{M}$

$(\mathbf{r} \mathbf{M}<\mathbf{r} \mathbf{Z})$

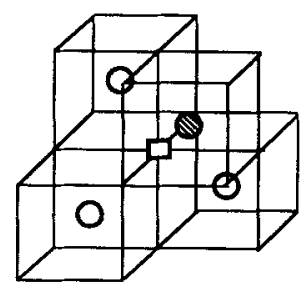

Model 2: $M-V_{0}-Z r$ $\left(\mathbf{r} \mathbf{M} \sim \mathbf{r Z r}_{\mathbf{r}}\right)$
Oxygen Vacancy

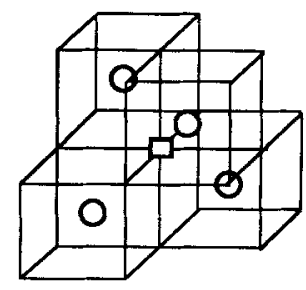

Model 3: $\mathrm{Zr}-\mathrm{V}_{\mathbf{0}}-\mathrm{Zr}$

$\left(\mathbf{r}_{\mathbf{M}}>\mathbf{r}_{\mathbf{Z r}}\right)$

Fig. 12. Schematic illustration of three models for cation-oxygen vacancy $\left(V_{0}\right)$ association. 
predicted from the $\mathrm{M}-V_{0}-\mathrm{Zr}$ model $\left(14 \mathrm{~mol} \% \mathrm{M}_{2} \mathrm{O}_{3}\right)$ is consistent with the experimental observation for $\mathrm{Sc}\left(13 \mathrm{~mol}_{0} \mathrm{Sc}_{2} \mathrm{O}_{3}\right)$. This coincidence is understandable in view of its ionic radius, $0.81 \AA$ (with 7-fold coordination based on Shannon's table ${ }^{37}$ ), which is much larger than those of $\mathrm{Fe}(0.65 \AA$, with 6 -fold coordination) and $\mathrm{Ga}(0.62 \AA$, with 6 -fold coordination) but comparable to that of $\operatorname{Zr}(0.84 \AA$, with 8-fold coordination, or $0.78 \AA$ with 7-fold coordination). The latter should allow $\mathrm{Sc}$ and $\mathrm{Zr}$ to share oxygen vacancies.

\section{Conclusions}

In our previous studies, we have concluded that, in zirconia solid solutions, $\mathrm{Zr}$ has its own characteristic local structure which is dopant-independent and phase-dependent. This conclusion is reaffirmed here and has been used to identify phases in very fine powders. Additional conclusions reached in the present work concerning trivalent dopants are as follows:

(1) They $\left(\mathrm{Gd}^{3+}, \mathrm{Y}^{3+}, \mathrm{Fe}^{3+}\right.$, and $\left.\mathrm{Ga}^{3+}\right)$ form solid solution with zirconia and have the same cation-cation distance as the host matrix. Undersized dopants cause much larger distortion of the neighboring cation network than oversized dopants because of the asymmetric interatomic potential.

(2) The local environments of dopants in zirconia solid solutions are phase-insensitive. Each dopant has a characteristic oxygen polyhedron $\left(\mathrm{MO}_{6}\right.$ for undersized dopants and $\mathrm{MO}_{8}$ for oversized dopants) with an $\mathrm{M}-\mathrm{O}$ bond length very different from that of $\mathrm{Zr}-\mathrm{O}$.

(3) Oxygen vacancies are associated with the $\mathrm{Zr}$ cations in the case of oversized dopants, and with two dopant cations in the case of undersized dopants. This different availability of oxygen vacancies to $\mathrm{Zr}$ is responsible for the different stabilization effects of oversized and undersized trivalent dopants.

\section{References}

'J. Lefèvre, "Fluorite-Type Structural Phase Modifications in Systems Having a Zirconium or Hafnium Oxide Base," Ann. Chim., 8, 117-49 (1963).

${ }^{2} R$. J. Stöcker, "Contribution a l'Étude des Properiétés des Solutions Solides Réfractaires, A Base de Zircone et de la Zircone Cubique," Ann. Chim., 1459$502(1960)$

"E. C. Subbarao, "Zirconia-An Overview"; pp. 1-24 in Advances in Ceramics, Vol. 3, Science and Technology of Zirconia I. Edited by A. H. Heuer and L. W. Hobbs. American Ceramic Society, Columbus, OH, 1981.

${ }^{4}$ M. Yoshimura, "Phase Stability of Zirconia," Am. Ceram. Soc. Bull., 67, $1950-55(1988)$

${ }^{5}$ T. S. Sheu, T-Y. Tien, and I-W. Chen, "Cubic-to-Tetragonal $\left(t^{\prime}\right)$ Transformation in Zirconia-Containing Systems," J. Am. Ceram. Soc., 75 [5] 1108-16 (1992).

"P. Li, I-W. Chen, and J. E. Penner-Hahn, "X-ray Absorption Studies of Zirconia Polymorphs. I. Local Characteristic Structure," Phys. Rev. B, 48 [14] 10063 73 (1993).

'P. Li. I-W. Chen, and J. E. Penner-Hahn, "X-ray Absorption Studies of Zirconia Polymorphs. II. Effect of $\mathrm{Y}_{2} \mathrm{O}_{3}$ Dopant on Zirconia Structure," Phys. Rev. B 48 [14] 10074-81 (1993)

${ }^{8}$ P. Li, I-W. Chen, and J. E. Penner-Hahn, "X-ray Absorption Studies of Zirco nia Polymorphs. III. Static Distortion and Thermal Distortion," Phys. Rev. B, 48 [14] 10082-89 (1993).

"S. M. Ho, "On the Structural Chemistry of Zirconium Oxide," Mater. Sci Eng. 54, 23-29(1982).

"J. Dexpert-Ghys, M. Faucher, and P. Caro, "Site Selective Spectroscopy and Structural Analysis of Yttria-Doped Zirconia," J. Solid State Chem., 54, 179-92 (1984)

"J. G. Allpress and H. J. Rossell, "Microdomain Description of Defective Fluorite-Type Phases $\mathrm{CaM}_{1,} \mathrm{O}_{2 \ldots}(\mathrm{M}=\mathrm{Zr}, \mathrm{Hf} ; x=0.1-0.2), " I$. Solid State Chem., 15, 68-78 (1975).

"M. Moringana, J. B. Cohen, and J. Faber Jr., "X-ray Diffraction Study of $\mathrm{Zr}(\mathrm{Ca}, \mathrm{Y}) \mathrm{O}, \ldots$. I. The Average Structure," Acta Crystallogr., A35, 789-95 (1979)

"C. J. Howard, R. J. Hill, and B. E. Reichert, "Structures of the $\mathrm{ZrO}_{2}$ Polymorphs at Room Temperature by High-Resolution Neutron Powder Diffraction," Acta Crustallogr, B44, 116-20 (1988).

${ }^{14}$ D. Steele and B. E. F. Fender, "The Structure of Cubic $\mathrm{ZrO}_{2}: \mathrm{YO}_{\mathrm{t} . S}$ Solid Solutions by Neutron Scattering," J. Phys. C: Solid State Phys., 7, 1 - 11 (1974).

${ }^{\text {Is }} \mathrm{S}$. Suzuki, M. Tanaka, and M. Ishigame, "Structural Studies on the ZrO$\mathrm{Y}_{2} \mathrm{O}_{3}$ System by Electron Diffraction and Electron Microscopy II," J. Phys. C: Solid State Phys., 20, 2693-72 (1987).

${ }^{1} \mathrm{M}$. H. Tuilier, J. Dexpert-Ghys, H. Dexpert, and P. Lagarde, "X-Ray Absorption Study of the $\mathrm{ZrO}_{2}-\mathrm{Y}_{2} \mathrm{O}_{3}$ System," J. Solid State Chem., 69, 153-61 (1987).

C. R. A. Catlow, A. V. Chadwick, G. N. Greaves, and L. M. Moroney, "EXAFS Study of Yltria-Stabilized Zirconia," J. Am. Ceram. Soc., 69, 272-77 (1986).
${ }^{38}$ B. W. Veal, A. G. Mckale, A. P. Paulikas, S. J. Rothman, and L. J. Nowicki, "EXAFS Study of Yttria Stabilized Cubic Zirconia," Physica B, 150, 234-40 (1988).

'"A. I. Goldman, E. Canova, Y. H. Kao, W. L. Roth, and R. Wang, "EXAFS Studies of Yttria Stabilized Zirconia"; pp. 442-44 in EXAFS and Near Edge Structure III. Edited by K. O. Hodgson, B. Hedman, and J. E. Penner-Hahn. Springer-Verlag, New York, 1984.

${ }^{20}$ H. Morikawa, Y. Shimizugawa, F. Marumo, T. Harasawa, H. Ikawa, $\mathrm{K}$. Tohji, and $\mathrm{Y}$. Udagawa, "Local Structure Around $\mathrm{Y}$ Atoms in $\mathrm{Y}_{2} \mathrm{O}_{3}-$ Stabilized Tetragonal $\mathrm{ZrO}_{2}$," J. Jpn. Ceram. Soc., 96, 253-58 (1988).

${ }^{21}$ 'T. Uehara, K. Koto, S. Emura, and F. Kanamaru, "EXAFS Study of the Fluorite and Pyrochlore Compounds in the System $\mathrm{ZrO}_{2}-\mathrm{Gd}_{2} \mathrm{O}_{3}$, Solid State lonics, 23, 331-37 (1987).

${ }^{22}$ Y. Shimizugawa, H. Morikawa, F. Marumo, A. Nakajima, K. Urabe, and M. Normura, "Local Structure Around Ce Atoms in $\mathrm{CeO}_{2}$-Stabilized Tetragonal $\mathrm{ZrO}_{2}$, " J. Jpn. Ceram. Soc., 95, 1131-33 (1987).

${ }^{29}$ Z. J. Shen, T. K. Li, K. Q. Lu, and Y. Q. Zhao, "An EXAFS Study of $\mathrm{Y}_{2} \mathrm{O}_{1}$-Stabilized $\mathrm{ZrO}_{2}$," J. Chin. Silic. Soc., 16 [3] 270-73 (1988).

${ }^{24}$ E. Zschech, G. Auerswald, E. D. Klinkenberg, and B. N. Novgorodov, "Short-Range Order in Yttria-Stabilized Zirconia: An EXAFS Study," Nucl. Instrum. Methods, A308, 255-59 (1991).

${ }^{25}$ D. Komyoji, A. Yoshiasa, T. Moriga, S. Emura, F. Kanamaru, and K. Koto, "EXAFS Study of the Fluorite-type Compounds in the Systems $(1-x) \mathrm{ZrO}_{2}$ $x \mathrm{YbO}_{1.5}(x=0.18 \sim 0.5)$ and $\mathrm{Zr}_{2} \mathrm{Ln}_{2} \mathrm{O}_{7}(\mathrm{Ln}=\mathrm{Tb}, \mathrm{Dy}, \mathrm{Ho}, \mathrm{Er}$, and $\mathrm{Yb}), "$ Solid State lonics, 50, 291-301 (1992).

${ }^{26}$ G. P. Williams, "Electron Binding Energies"; pp. 2-5 in X-Ray Booklet, Lawrence Berkeley Laboratory, University of California, Berkeley, CA, 1986.

${ }^{27}$ B. K. Teo, EXAFS: Basic Principles and Data Analysis. Springer-Verlag, New York, 1986.

${ }^{28} \mathrm{R}$. A. Scott, "Measurement of Metal-Ligand Distances by EXAFS," Methods Enzymol, 177, 414-59 (1985).

${ }^{2{ }^{2}}$ J. J. Rehr, J. Mustre de Leon, S. I. Zabinsky, and R. C. Albers, "Theoretical $\mathrm{X}$-ray Absorption Fine Structure Standards," J.Am. Chem. Soc., 113, 5135 (1991).

${ }^{30} \mathrm{G}$. S. Waldo and J. E. Penner-Hahn; unpublished work.

${ }^{31}$ D. K. Smith and H. W. Newkirk, "The Crystal Structure of Baddeleyite (Monoclinic $\mathrm{ZrO}_{2}$ ) and Its Relation to the Polymorphism of $\mathrm{ZrO}_{2}$, Acta Crystallogr., 18, 983-91 (1965).

${ }^{32} \mathrm{M}$. Faucher and J. Pannetier, "Refinement of the $\mathrm{Y}_{2} \mathrm{O}_{3}$ Structure at $77 \mathrm{~K}$," Acta Crystallogr., B36, 3209-11 (1980).

${ }^{33}$ A. L. Roe, D. J. Schneider, R. J. Mayer, J. W. Pyrz, J. Widom, and L. Que, Jr., "X-ray Absorption Spectroscopy of Iron-Tyrosinate Proteins," J. Am. Chem. Soc., 106, 1676-81 (1984)

${ }^{34}$ J. E. Hahn, R. A. Scott, K. O. Hodgson, S. Doniach, S. R. Desjardiins, and E. I. Solomon, "Observation of an Electric Quadrupole Transition in the X-ray Absorption Spectrum of a Cu(II) Complex," Chem. Phys. Lett., 88, 595-98 (1982).

${ }^{35}$ A. F. Wells, Structural Inorganic Chemistry, 5th ed. Clarendon Press, Oxford, U.K., 1986

${ }^{36} \mathrm{~S}$. Geller, "Crystal Structure of $\beta-\mathrm{Ga}_{2} \mathrm{O}_{3}, "$ J. Chem. Phys., 33, 676-84 (1960).

${ }^{7}$ R. D. Shannon, "Revised Effective Ionic Radii and Systematic Studies of Interatomic Distances in Halides and Chalcogenides," Acta Crystallogr., A32, $751-67$ (1976).

${ }^{38}$ A. I. Komkov, "The Structure of Natural Fergusonite, and of a Polymorphic Modification," Kristallografiya, 4, 836-41 (1959).

${ }^{30} \mathrm{~L}$. H. Brixner and H. Y. Chen, "On the Structural and Luminescent Properties of $\mathrm{M}^{\prime} \mathrm{LnTaO}_{4}$ Rare Earth Tantalates," J. Electrochem. Soc.: Solid State Sci. Technol., 130, 2435-43 (1983).

${ }^{40} A$. R. Chetal, P. Mahta, and P. R. Sarode, "X-ray Absorption Fine Structure Study of Some Compounds and Complexes of Samariurn and Gadolinium," J. Less-Common Met., 167, 199-211 (1991).

${ }^{41} \mathrm{P}$. Li, I-W. Chen, and J. E. Penner-Hahn, "The Effect of Dopants on Zirconia Stabilization-An X-ray Absorption Study. III. Pentavalent Dopants," J. Am. Ceram. Soc., in press.

${ }^{42}$ A. Dwivedi and A. N. Cormack, "A Computer Simulation Study of the Defect Structure of Calcia-Stabilized Zirconia," Philos. Mag. A, 61 [1] 1-22 (1990).

"IJ. N. Karavaev, S. F. Paiguev, and A. D. Neujmin, "Solubility of Iron, Chromium and Titanium Oxides in $\mathrm{ZrO}_{2}$ Based Solid Solutions"; pp. 247-52 in High Tech Ceramics. Edited by P. Vincenzini. Elsevier Science Publishers B. V., Amsterdam, Netherlands, 1987.

${ }^{44}$ R. V. Wilhelm, Ir., D. S. Howarth, "Iron Oxide Doped Yttria-Stabilized Zirconia Ceramic: Iron Solubility and Electrical Conductivity," Am. Ceram. Soc. Bull., 58, 228-32 (1979).

${ }^{45}$ P. J. Alonso, R. Alcalá, J. Casas-Gonzalez, R. Cases, and V. M. Orera, "Spectroscopy of Chromium(III) in Yttrium-Stabilized $\mathrm{ZrO}_{2}, "$ I. Phys. Chem. Solids, 50, 1185-91 (1989).

${ }^{4} \mathrm{P}$. Li, I-W. Chen, J. E. Penner-Hahn, and T-Y. Tien, "X-ray Absorption Studies of Ceria with Trivalent Dopants," J. Am. Ceram. Soc., 74 [5] 958-67 (1991).

${ }^{n}$ M. Jayaratna, M. Yoshimura, and S. Sõmiya, "Electrical Conductivity of $\mathrm{Cr}_{2} \mathrm{O}_{3}$-Doped $\mathrm{Y}_{2} \mathrm{O}_{3}$-Stabilized $\mathrm{ZrO}_{2}, "$ J. Mater. Sci., 22, 2011-16 (1987).

4"R. H. G. Kiminami, "The Monoclinic-Tetragonal Phase Transformation of Zirconia in the System $\mathrm{ZrO}_{2}-\mathrm{Fe}_{2} \mathrm{O}_{3}, " J$. Mater. Sci. Lett., 9, 373-74(1990).

${ }^{44} \mathrm{M}$. Yoshimura, M. Yashima, and T. Noma, "Formation of Diffusionlessly Transformed Tetragonal Phase by Rapid Quenching of Melts in $\mathrm{ZrO}_{2}-\mathrm{RO}_{1.5}$ Systems $(\mathrm{R}=$ Rare Earths)," J. Mater. Sci., 25, 2011-16(1990). 